\title{
Surface expression of Mediterranean Water dipoles and their contribution to the shelf/slope - open ocean exchange
}

\author{
N. Serra ${ }^{1,2}$, I. Ambar ${ }^{2}$, and D. Boutov ${ }^{2}$ \\ ${ }^{1}$ Institut für Meereskunde, Universität Hamburg, Germany \\ ${ }^{2}$ Centro de Oceanografia, Faculdade de Ciências da Universidade de Lisboa, Portugal
}

Received: 15 October 2009 - Published in Ocean Sci. Discuss.: 11 November 2009

Revised: 2 February 2010 - Accepted: 5 February 2010 - Published: 9 February 2010

\begin{abstract}
The generation of dipolar eddies within the Mediterranean Water (MW) layers, at the Portuguese continental slope, was observed using subsurface RAFOS floats. The surface expression of these mid-depth dipoles is here characterized with remote sensing data, namely with sea surface temperature, chlorophyll concentration and sea surface height measurements. Two cases are presented demonstrating the remote detection of these underwater structures in the Gulf of Cadiz during 1998 and 2001. The presence of subsurface MW dipoles in the Iberian coastal zone is shown to influence the development of coastal upwelling filaments. The surface circulation induced by the dipoles causes the upwelling filaments to extend offshorewards and thus to enhance the transport of physical, chemical and biological properties into the open ocean. A numerical model simulation of the ocean circulation around the Iberian Peninsula forced by heat and freshwater fluxes (computed using the NCEP reanalysis atmospheric state) and by the overflow of MW at the Strait of Gibraltar, corroborates the connection between the surface and the mid-depth flows. The highresolution numerical experiment is used to help clarifying the occurrence of the MW dipoles surface expression and the impact of these dipoles on the eddy kinetic energy of the upper ocean and on the exchange of volume and salt between the shelf/slope and the open ocean.
\end{abstract}

\section{Introduction}

The Mediterranean Water (MW) spreads in the northeastern part of the Gulf of Cadiz as a bottom-gravity current (Ambar and Howe, 1979; Baringer and Price, 1997). Approaching

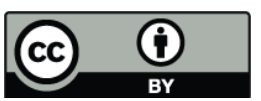

Correspondence to: N. Serra

(nuno.serra@zmaw.de) the Portimao Canyon (around $8^{\circ} \mathrm{W}$ ), the flow stabilizes in the water column and continues flowing against the Iberian continental slope as a wall-bounded mid-depth intensified jet known as MW Undercurrent. This current persists along the Atlantic eastern boundary and is thought to reach latitudes of up to $55^{\circ} \mathrm{N}$. Along its path, the current at times separates from the slope forming eddies. These eddies (termed meddies) are coherent vortices rotating anticyclonically and enclosing in their cores the MW high salinity and temperature anomaly. Their dimensions range from 25 to $100 \mathrm{~km}$ in diameter, in the vertical they can extend up to $800 \mathrm{~m}$, their average azimuthal velocity is $0.3 \mathrm{~ms}^{-1}$ and their typical drift speed is in the range $0.02-0.04 \mathrm{~ms}^{-1}$, although it can vary due to advection by background currents and/or eddy interactions.

Many studies dealt with the characterization of the physical and dynamical aspects of meddies and these were carried out prior to the clear identification of the generation sites. Meddies were first found in the Canary basin as isolated monopolar structures (e.g., Armi and Zenk, 1984; Armi et al., 1989; Schultz-Tokos and Rossby, 1991) and later in the Iberian basin (e.g., Käse et al., 1989; Zenk et al., 1992; Pingree and Cann, 1993). However, meddies were mostly observed at locations westwards from Cape St. Vincent $\left(9^{\circ} \mathrm{W}\right.$; $37^{\circ} \mathrm{N}$ ). An exception was the meddy found by Prater and Sanford (1994), which was east of that Cape. A few meddy generation sites have been established and observations have given some insight into the generation mechanisms involved. Bower et al. (1997) concluded that Cape St. Vincent and the Estremadura Promontory are sites for meddy generation. Other studies also pointed to meddy generation related with the Undercurrent separation at Cape Finisterre (Paillet et al., 1999) and at the Gorringe Bank (Serra and Ambar, 2002) and with the Undercurrent instability promoted by the Portimao Canyon (Chérubin et al., 2000; Serra and Ambar, 2002).

Published by Copernicus Publications on behalf of the European Geosciences Union. 
Cyclonically rotating vortices have been also found within or below the MW layers (Swallow, 1969; Schauer, 1989), but no clear relation with the meddies was established in these earlier studies. Some authors reported the interaction between different meddies. Schultz-Tokos et al. (1994) observed the merging of two meddies and Carton et al. (2002) reported the interaction between two meddies and a cyclone in the southern Gulf of Cadiz. The coupling between cyclones and anticyclones was investigated numerically in Käse and Zenk (1996), the authors having recognized the cyclone's importance for the meddy movement. Sporadic float observations of cyclone-anticyclone coupling were reported in Richardson et al. (2000). In situ observations and physical simulations have shown that cyclones also play an important role in the generation of meddies, by helping its detachment from the Undercurrent at Cape St. Vincent by means of dipole formation (Sadoux et al., 2000; Serra et al., 2002). The definite clear identification of MW dipoles was reported in Serra and Ambar (2002).

A large amount of theoretical, physical and numerical studies has been devoted to the generation and movement of dipolar structures in homogeneous or stratified flows, either on the $f$ or on the $\beta$ plane (e.g., Mied et al., 1991; VelascoFuentes and van Heijst, 1994; Eames and Flór, 1998). The dipole, also termed modon, is an exact nonlinear solution of the quasi-geostrophic potential vorticity equation (Flierl et al., 1980). It consists of a quasi-symmetric current system (two vortices with opposite sign rotation - anticyclone and cyclone) that distributes passive tracers in a way forming mushroom-like patterns. According to Fedorov (1986), the dipole is one of the most widespread forms of non-stationary and non-linear motion in the ocean. Many studies reported observations of surface layer dipolar structures using remote sensing methods (e.g., Ginzburg et al., 2002; Afansyev et al., 2002) and the important contribution of these dipoles to the coastal/deep-basin water exchange was recognized. Due to their high drift speed, the dipoles are able to advect properties very efficiently. In particular, they are able to redistribute nutrients in the coastal area.

The generation of dipoles in the MW Undercurrent is localized in places where there is a lateral injection of weakly stratified (low-potential vorticity) water into an almost quiescent environment, in this case the ocean interior. Thus, the separation of the Undercurrent from the slope forced by a topographic constraint is a necessary condition (Serra et al., 2005). This separated patch is an input of momentum into the interior. The simplest form of response to this localized (almost point-source) momentum is the generation of counter-rotating vortices. Laboratory measurements (Baey et al., 1995) showed that dipolar vortices could be generated by this momentum input in a homogeneous rotating environment.

The surface detection of deep meddies using surface drifters or hydrological measurements was reported in the past (Käse and Zenk, 1989; Schultz-Tokos et al., 1994; Pin- gree and Cann, 1993; Pingree, 1995). Stammer et al. (1991) were able to correlate positively the altimetry signal with the dynamic height at the MW level. Oliveira et al. (2000) showed the existence of SST patterns whose shape was consistent with the circulation induced by meddies revealed by the AMUSE project RAFOS floats (Bower et al., 1997). The authors concluded that a necessary condition for the surface recognition of meddies is the existence of surface thermal gradients that could act as tracers for the eddy movement.

The most prominent feature of the upper ocean dynamics off the western Iberian Peninsula is its coastal upwelling. Coastal upwelling is a wind-driven phenomenon usually connected with a decrease of SST and an increase of primary production in the coastal ocean. It occurs under wind favourable conditions (coast on the left of the wind direction in the Northern Hemisphere) along the eastern sides of the major ocean basins, as a consequence of Ekman offshore transport and resulting surface divergence along the coast. Due to mass continuity, this surface divergence induces an ascending motion (upwelling) of subsurface water which is usually colder and nutrient richer than the surface water. Besides the cross-slope thermal gradient, it also creates a sea surface slope, giving rise, by geostrophic adjustment, to an equatorward jet parallel to the coast. If the upwelling-favourable wind blows for sufficient time, a thermal and density front forms which separates cold coastal waters from warmer offshore waters and where horizontal velocity shear causes barotropic and baroclinic instabilities. The export of upwelled water to the open ocean is locally enhanced by meanders and the associated development of filament structures extending offshore. Filaments export a much larger mass along their principal axis than expected by Ekman circulation, thus constituting an important mechanism of exchange between coastal and deep sea waters (Relvas et al., 2007).

The Iberian coastal upwelling is a seasonal phenomenon starting in late spring/early summer as a response to predominantly northerly winds. The near surface wind field is basically controlled by the Azores high, the centre of which migrates along $38^{\circ} \mathrm{W}$, from $27^{\circ}$ to $33^{\circ} \mathrm{N}$ between March and August. The associated atmospheric circulation off Iberia changes from weak westerly winds in winter to northerly and northwesterly stronger winds in summer (Fiúza, 1982). Both observations and modelling (Oliveira et al., 2009) show a decrease in SST of about $2-2.5^{\circ} \mathrm{C}$ along the coast during the wind intensification phase with a one-day lag between the peak of northerly winds and minimum SST.

The generated upwelling front is characterized by sharp lateral gradients in velocity, density and biological fields. In SST images off Iberia, besides filaments, smaller scale instabilities with wavelengths of about $15-30 \mathrm{~km}$ are visible (Shi and Røed, 1999). Haynes et al. (1993) presented three formation mechanisms of filaments: dynamical instability, topographic forcing and geostrophic turbulence. Filaments off Iberia show relatively weak dynamical structure, with the 
offshore flow restricted to the 100-m surface layer, as a result of surface-trapped horizontal density gradients (Relvas et al., 2007). A portion of the water transported offshore from the shelf re-circulates back on time scales of about 1 month (Barton et al., 2001). Filaments off Iberia are recurrently located in several fixed points (around $41^{\circ} \mathrm{N}, 40^{\circ} \mathrm{N}, 38.5^{\circ} \mathrm{N}, 38^{\circ} \mathrm{N}$ and $37^{\circ} \mathrm{N}$ ), which seem to be systematically associated with irregularities of the bathymetry or of the coastline (Fiúza, 1982; Sousa and Bricaud, 1992; Haynes et al., 1993). This systematic association led Røed and Shi (1999) to investigate the effect of irregularities in the bathymetry and coastline geometry on the formation, evolution and persistence of cool filaments and other mesoscale structures in the coastal upwelling regions. They concluded that the preferred spacing of the filaments does not inherently depend on the existence of those irregularities but rather on barotropic and baroclinic instabilities. However the bathymetry and coastline geometry irregularities are relevant for anchoring the filaments.

The upwelling filaments can reach $30-50 \mathrm{~km}$ offshore under calm conditions and $100-200 \mathrm{~km}$ during or shortly after strong winds (Fiúza, 1983). Although they are predominately driven by wind, the impact of the circulation induced by eddies in the filament offshore extension has not been clearly shown. This motivated our study, with two objectives: first to present two cases where the surface detection of MW dipoles could be established based on four distinct data sources, one in-situ and three satellite-derived; second to demonstrate the role that sub-surface eddies (like meddies) can play in momentum and property transfer from the shelf/slope to the deep-ocean. For that purpose, we analyze results from a high-resolution numerical simulation of the MW spreading off southern and western Iberia and its interaction with the upper layers. Evidence will be given for a clear interaction between the MW undercurrent and associated eddies and the surface circulation, which is mostly relevant for the across-slope exchange of physical and biogeochemical properties between the shelf and the deep-ocean. The interaction here presented, although being particular to the Iberian Atlantic coastal zone, where the MW undercurrent sheds energetic eddies, is certainly ubiquitous and should be present in all major World Ocean upwelling systems (degree of importance to be determined), in particular in those where deep undercurrents are present and prone to develop instabilities and generate eddies (for instance the California and the Benguela Current upwelling systems).

The paper is organized as follows. The observational data and the numerical model set-up are presented in Sect. 2, followed by the description of the MW dipole observations in Sect. 3. There, float trajectories are presented and the surface expression of vortices is demonstrated using sea surface temperatures (SST), chlorophyll concentrations (CHL) and sea surface height (SSH) anomalies. Section 4 presents results from the numerical simulations focusing on the interaction between the MW dipoles and the upper-ocean circulation. The main conclusions are summarized in Sect. 5.

\section{In situ/satellite data and numerical model set-up}

During the CANIGO and MEDTOP projects, 24 and 32 isobaric RAFOS floats, respectively, were seeded in the MW Undercurrent upstream of the Portimao Canyon (grey box in Fig. 1). The floats were deployed in the MW layer (nominal depths varying between $800 \mathrm{~m}$ and $1200 \mathrm{~m}$ ) during five large-scale CTD cruises: two during CANIGO, in September 1997 and January 1998, and three during MEDTOP, in February, May and September 2001. The hydrological surveys were conducted to characterize the body of MW in the area and help to choose the RAFOS deployment sites. During CANIGO some floats were also deployed from aboard a sailing vessel after a quick XBT survey. The temporal cover of the float database is from September 1997 to July 1999 and from February 2001 to September 2002. More details on the observational strategies and results from the CANIGO and MEDTOP projects can be found, respectively, in Serra and Ambar (2002) and in Ambar et al. (2008).

NOAA-12 and NOAA-14 AVHRR sensor data were received and processed at the HRPT satellite receiving station of the Centro de Oceanografia da Universidade de Lisboa, Portugal. In the present analysis, only brightness temperature of AVHRR channel 4 was considered, since the algorithms that use a combination of different infrared channels to correct for atmospheric effects introduce a noise amplification factor that is not suitable to characterize spatial patterns (Oliveira et al., 2000). Clouds were separately detected through a multi-band algorithm, which is part of the Multi Channel Sea Surface Temperature - MCSST - processing. The HRPT ocean colour images were received by the Maspalomas Space Center, Canary Islands, Spain, and processed at the Centro de Oceanografia da Universidade de Lisboa. In the present work, the chl- $a$ concentration parameter is used. All HRPT images have a horizontal resolution of $1.1 \mathrm{~km}$.

The altimetry data used here consist in maps of SSH anomaly (SSHA) derived from a merging of ERS-1/2 and Topex/Poseidon data (LeTraon and Ogor, 1998) and were supplied by AVISO. All the altimetry data was corrected for instrumental noise, atmospheric effects, ocean surface waves, tides and the inverse barometer effect. The anomalies were constructed from the sea surface heights by subtracting a 3-year mean from each satellite track of a given cycle. The horizontal distributions of SSHA were produced using a space/time objective analysis (LeTraon et al., 1998). The merging of the Topex/Poseidon and ERS-1/2 provides an improved space-time sampling of the ocean, since it takes profit from both the higher temporal resolution of Topex/Poseidon and the higher spatial resolution of ERS-1/2. The final horizontal resolution of the SSHA maps is 0.25 degrees both in latitude and longitude. The database temporal resolution is 10 days.

The model used in this study is the $z$-coordinate MIT general circulation model (Marshall et al., 1997). The model was configured to the Northeast Atlantic and Western 


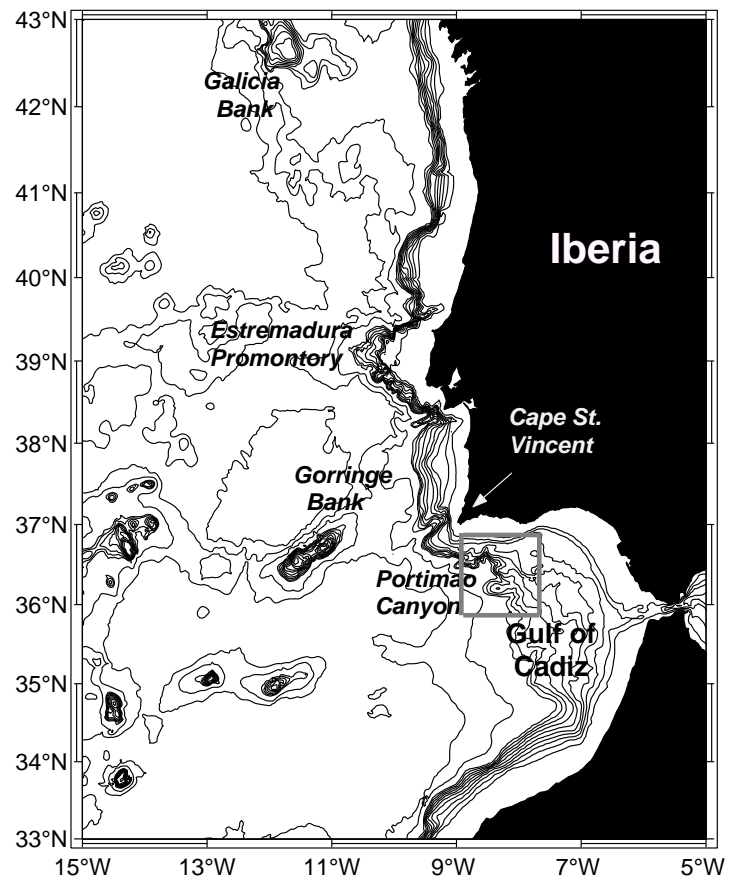

Fig. 1. Map of the region showing the names of the major bathymetric features. The contour interval is $200 \mathrm{~m}$ from $200-2000 \mathrm{~m}$ and $1000 \mathrm{~m}$ from $2000-5000 \mathrm{~m}$.

Mediterranean regions, extending from $9^{\circ} \mathrm{E}$ to $24^{\circ} \mathrm{W}$ and from $30^{\circ} \mathrm{N}$ to $48^{\circ} \mathrm{N}$, and has a resolution of $1 / 30^{\circ}$ (approx. $2.8 \mathrm{~km}$ ). In the vertical, 140 levels are used, with vertical resolution varying from $5 \mathrm{~m}$ in the upper ocean to $100 \mathrm{~m}$ in the deep ocean. The model bottom topography derives from ETOPO2 and the initial temperature and salinity conditions from the January values of the World Ocean Atlas 2005 (Boyer et al., 2005). The model is forced at the surface by fluxes of momentum, heat and freshwater computed using bulk formulae and the 6-hourly atmospheric state from the NCEP reanalysis 1 (Kalnay et al., 1996). At the volumebalanced open boundaries, the model is forced by a $1 / 6^{\circ}$ resolution Atlantic solution of the MITgcm forced by the same NCEP dataset. Vertical mixing is parameterized by the KPP formulation of Large et al. (1994). Background biharmonic coefficients of horizontal diffusion and viscosity are, respectively, $1 \times 10^{3} \mathrm{~m}^{4} \mathrm{~s}^{-1}$ and $5 \times 10^{8} \mathrm{~m}^{4} \mathrm{~s}^{-1}$. Background laplacian coefficients of vertical diffusion and viscosity were both $1 \times 10^{-4} \mathrm{~m}^{2} \mathrm{~s}^{-1}$. Contrary to other published simulations at similar horizontal resolution (Drillet et al., 2005), sea surface or interior temperature and salinity relaxation was not applied. Due to computational limitations, the model was only integrated for 6 years starting at year 1990. The results here presented correspond to the 3-year period 1993-1995. All the analyses will be based on daily model output. A previous unforced model run, using a sigma-coordinate model, was analysed by Serra et al. (2005), focusing on the MW plume topographic splitting and meddy generation mechanisms. In this work, we build from past results, extend the experiment to the surface and laterally forced case and further focus on the vertical structure of the model generated MW eddies and their interaction with the upper layers.

\section{Observations of MW dipoles and their surface expression}

\subsection{CANIGO 1998 observations}

\subsubsection{Float trajectories}

In order to visualize the temporal evolution of the flow field, float trajectories were segmented in periods of 40 days. Figure 2 presents the results from the CANIGO study, from 22 February 1998 (53/98) to 20 October 1998 (293/98), showing one meddy-cyclone (M1-C1) coupling at Cape St. Vincent and two dipole formations (M2-C2, M4-C4) off the Portuguese southern continental slope near the Portimao Canyon. These float observations have been extensively reported before in Serra and Ambar (2002). Here they are only briefly presented in order to introduce the location of the eddies detected using satellite remote sensing data.

During the period 53/98 to $133 / 98$, cyclone C1 moves westwards towards Cape St. Vincent and interacts with meddy M1 promoting its detachment. $\mathrm{C} 1$ and M1 travel as a dipolar structure until reaching the Gorringe Bank (a seamount as shallow as $100 \mathrm{~m}$ ), which further splits the structure back into two single eddies (see period 93/98 to 133/98). After 133/98, meddy M1 could not be further followed since the float left the eddy. Cyclone $\mathrm{C} 1$ was intensified at $500 \mathrm{~m}$ depth, slightly above the MW layers, as concluded from the geostrophic flow computed with CTD data collected during the February 1998 CANIGO survey taken prior to the floats deployment (Serra and Ambar, 2002).

The second MW dipole (M2-C2) can be seen in the period $133 / 98$ to $173 / 98$, immediately after generation. Two floats revealed the anticyclonic counterpart (the meddy) and one float its cyclonic pole. During 173/98 to 213/98, the dipole moved south and the float that once was in the meddy entered the cyclone and sampled it along the rest of its operating cycle. Cyclone $\mathrm{C} 2$ continued along the slope to the north (213/98 to 253/98). The third MW dipole revealed by the floats (M4-C4) was again shed from the MW Undercurrent near Portimao Canyon (period 253/98 to 293/98). A float drifting at $1200 \mathrm{~m}$ revealed cyclone $\mathrm{C} 4$, whereas meddy M4 was revealed by a $800 \mathrm{~m}$ float. $\mathrm{C} 4$ was further followed for more than 30 days while moving westwards south of the Gorringe Bank (not shown).

\subsubsection{Surface tracer patterns}

The methodology followed to assess the surface expression of the located MW eddies consists in the superposition of all float data on remote sensing images and the establishment of 

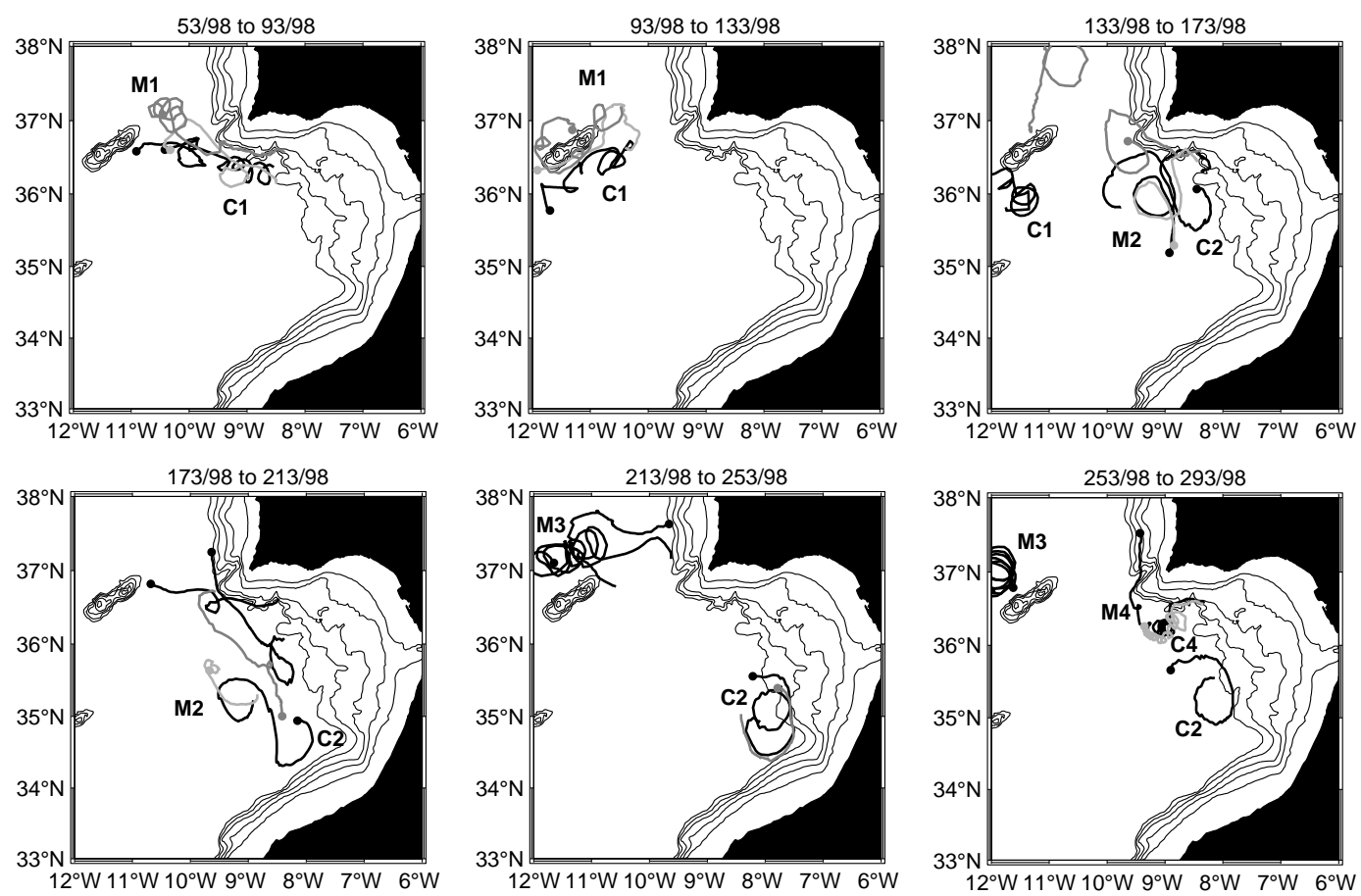

Fig. 2. Sequence of snapshots with floats trajectories divided in periods of 40 days from julian days 53/98 to 293/98 (CANIGO project). Black trajectories correspond to floats operating at depths between $700 \mathrm{~m}$ and $1000 \mathrm{~m}$ and grey trajectories to floats drifting between $1000 \mathrm{~m}$ and $1300 \mathrm{~m}$ (the dot corresponds to the float last position in the shown period). Label $\mathrm{M}$ refers to meddies and label $\mathrm{C}$ to cyclones. Bathymetry is contoured from $200 \mathrm{~m}$ to $1800 \mathrm{~m}$ depth with a spacing of $400 \mathrm{~m}$.

surface patterns that are related with the deep eddies. Figure 3 shows a sequence of SST maps illustrating the surface detection of CANIGO dipole M2-C2 during about 3 months, from mid-June 1998 to mid-September 1998. The colour palette stretching is not the same for all maps and was chosen to enhance the structures of interest, so, an image-to-image colour correspondence should not be attempted. The term SST is here used to represent the infrared channel 4 radiation temperatures instead of true sea surface temperatures.

A strong thermal gradient is present in the coastal region, with lower temperatures against the coast due to upwelling. In Fig. 3a, the SST distribution from 12 June 1998 (163/98) shows two mushroom-like patterns centred, respectively at the longitudes $9^{\circ} \mathrm{W}$ and $10.25^{\circ} \mathrm{W}$. These surface features reveal the influence of the presence of MW eddies, as shown by the underwater trajectories superimposed on the image. The subsequent maps illustrate the evolution of the SST pattern. A clear correspondence between the eastern mushroom feature and MW dipole M2-C2 is evident. Cold water is brought southwards between M2 and C2 (Fig. 3b) and wraps around the eddy centres. Dipole M2-C2 moved south and so did the SST dipolar pattern, which by 12 July 1998 (193/98) was about $50 \mathrm{~km}$ south (Fig. 3d) of its position in the first map. From this image to its next in the sequence one can clearly see the transition of the float from one pole to the counterpart. Thirteen days later (Fig. 3f) on 6 August 1998 (218/98), the cyclone seems intensified since the surface pattern shows more water being wrapped around the structure. Meddy M2 is still discernible but the separation relative to cyclone $\mathrm{C} 2$ has increased. From there on the meddy could not be detected, but the SST cyclonic pattern is still evident and consistent with the C2 RAFOS trajectory.

The replenishment of nutrients brought by the upwelled waters into the photic zone allows phytoplankton growth inshorewards of the upwelling front, the offshore side of it remaining oligotrophic. The resulting coastal zone high chl$a$ concentration is thus suitable to be used as a passive tracer of the circulation over the shelf/slope. The distribution of SeaWiFS chl- $a$ concentration from 169/98 (Fig. 4) is characterized by high concentrations $\left(>1 \mathrm{mgm}^{-3}\right)$ present along the Iberian and African coasts (higher in the former) confined to the continental shelf. The images have a stretched colour palette in order to cover the whole range of concentrations.

Offshore from the 1800-m bathymetric line, only three mushroom-like patterns congregate concentrations above the background. All three patterns can be directly linked to the presence of MW layer eddies. The patterns centred at $9^{\circ} \mathrm{W}$ and $10^{\circ} \mathrm{W}$ correspond to the features present in the SST image of the same day shown in Fig. 3b. It is thus clear that MW dipoles induce the offshoreward transport of chlorophyll pigments from the shelf/slope region. It is also interesting to notice that the stem of the mushroom is where larger 


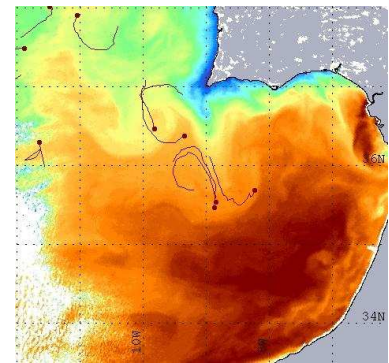

(a)

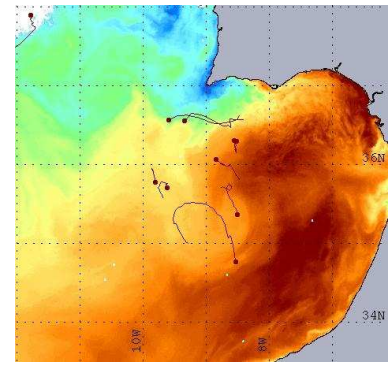

(d)

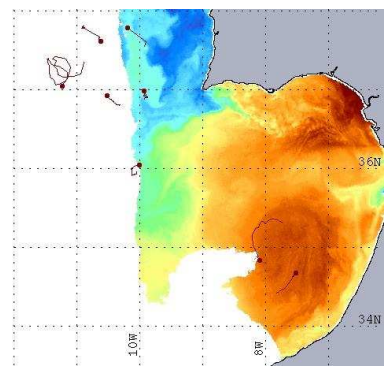

(g)

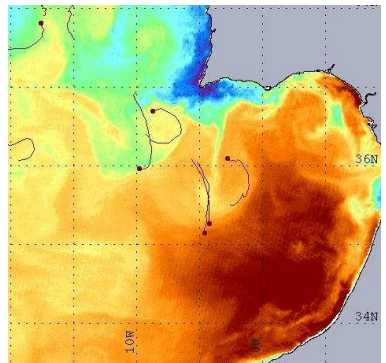

(b)

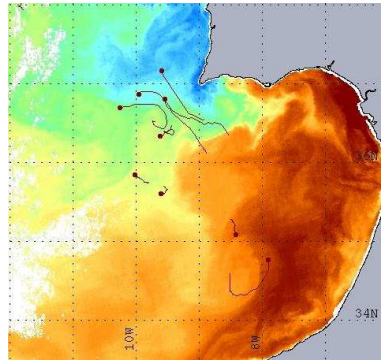

(e)

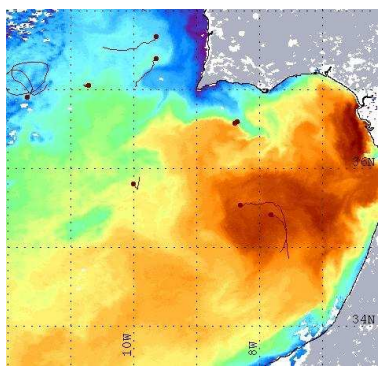

(h)

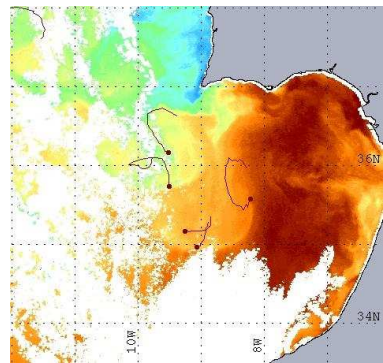

(c)

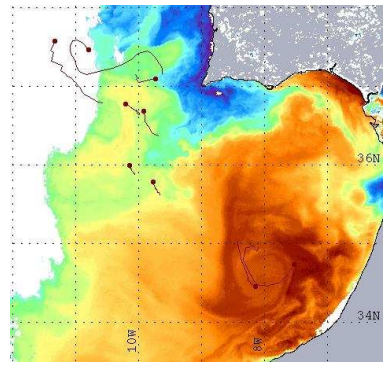

(f)

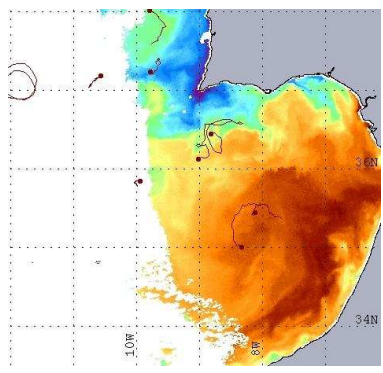

(i)

Fig. 3. SST images showing the surface signature of one dipolar structure found during CANIGO for (a) 12 June 1998 (163/98), (b) 18 June 1998 (169/98), (c) 26 June 1998 (177/98), (d) 12 July 1998 (193/98), (e) 24 July 1998 (205/98), (f) 6 August 1998 (218/98), (g) 22 August 1998 (234/98), (h) 6 September 1998 (249/98), (i) 14 September 1998 (257/98). Underwater float trajectories (image date \pm 5 days) are superimposed (depth ranges from $700 \mathrm{~m}$ to $1300 \mathrm{~m}$; the dot corresponds to the float last position). The colorbar is not presented since values are irrelevant for the pattern identification (blue tones correspond to cold water and orange/red tones to warm water).

concentrations occur; also colder water was found there. The velocities in the middle of the dipoles, which are a composition of the velocities of both eddies, are sufficiently strong to capture water from the shelf and advect it for hundreds of $\mathrm{km}$. Another interesting aspect is the concentrations being larger in the cyclonic part of the dipole system. Either there is intense upwelling in the cyclones with the consequent higher productivity there, or, more likely, the cyclone resides closer to the surface and is more efficient in capturing the high concentrations when closer to the shelf/slope region.

\subsubsection{Surface dynamical field}

The surface dynamical field associated with dipole M2-C2 is here assessed by using SSHA and corresponding relative geostrophic velocity anomalies. As stated before, the SSH anomaly was constructed by subtracting a time average from each point along the track of the satellite. This removes the undesired contribution of the geoid, but also the contribution for the surface slopes from any permanent current that might exist in the region, like for instance the Azores or the Portugal Current. The velocities computed from anomalies of surface slopes are thus velocity anomalies relative to the averaged state. The anomalies might be associated to persistent eddies if they are strong enough to stand out from the background field. This is the case presented in Fig. 5, where the trajectories of three RAFOS floats are superimposed on SSHA and corresponding geostrophic anomaly current vectors. A good agreeement between the dipole float track and the SSHA exists. In the map from 13 July 1998 (194/98), a positive SSHA (which means anticyclonic flow) is close to a negative anomaly (cyclonic flow) in the region $34.5^{\circ} \mathrm{N}-$ $36^{\circ} \mathrm{N}$ and $10^{\circ} \mathrm{W}-8^{\circ} \mathrm{W}$. Geostrophic velocity anomalies of 


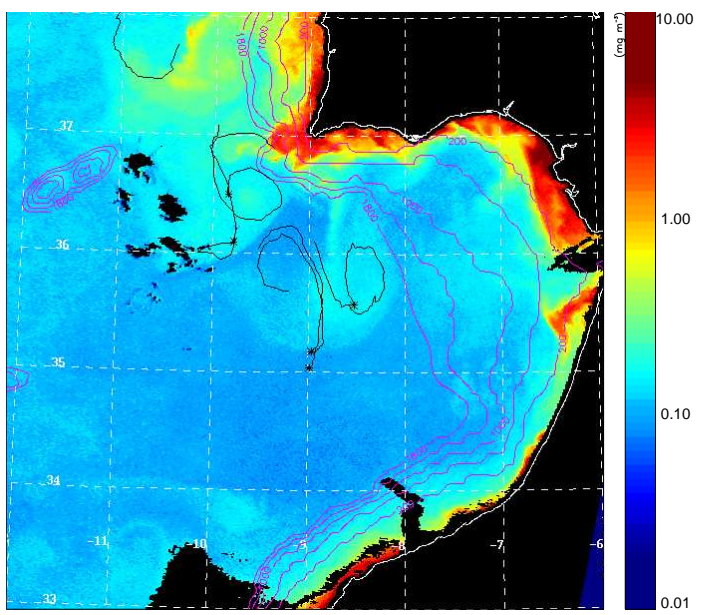

Fig. 4. Chlorophyll- $a$ concentration distribution (units: $\mathrm{mgm}^{-3}$ ) in 18 June 1998 (169/98) with RAFOS float trajectories overlaid (float depths range from $700 \mathrm{~m}$ to $1300 \mathrm{~m}$; the asterisks correspond to the floats last position), showing the surface expression of one CANIGO dipole. Bathymetry is contoured from $200 \mathrm{~m}$ to $1800 \mathrm{~m}$ depth with a spacing of $400 \mathrm{~m}$.

typically $0.1 \mathrm{~ms}^{-1}$ are associated to these two SSHA but are higher $\left(>0.2 \mathrm{~ms}^{-1}\right)$ between them. The next SSHA map, from 12 August 1998 (224/98), shows both vortical centres further south and more horizontally separated, which is consistent to what was observed with the SST images concerning meddy $\mathrm{M} 2$ and cyclone $\mathrm{C} 2$. The cyclone intensified in the last shown period as can be seen by the increase of the velocity anomalies (Fig. $5 \mathrm{~b}$ and c). Also the cyclonic SSHA turned more symmetric indicating that $\mathrm{C} 2$ was free of strong interactions with other eddies.

\subsection{MEDTOP 2001 observations}

\subsubsection{Float trajectories}

Selected MEDTOP floats were also segmented in periods of 40 days from 22 February 2001 (53/01) to 20 October 2001 (293/01) and show the presence of a dipole in the central part of the Gulf of Cadiz (Fig. 6). In the period 93/01 to $133 / 01$, meddy M5, which was formed close to the slope in the Portimao Canyon region, moved swiftly to the southwest (average drift speed of $0.05 \mathrm{~ms}^{-1}$ ) and merged with a larger meddy (M6) that was centred at $36^{\circ} \mathrm{N}, 10^{\circ} \mathrm{W}$. This was concluded by the sudden change in the RAFOS loop diameter accompanied by almost constant temperatures registered during the process (not shown). The float moved south in this new structure at an average drift speed of $0.03 \mathrm{~ms}^{-1}$. In the next time period (133/01 to $173 / 01)$ the structure turned to the southeast direction heading to the Moroccan slope with the drift speed increasing to $0.04 \mathrm{~ms}^{-1}$. During the same period meddy M7 and cyclone C7 are present further north. Some of the float trajectories in the following 80 days (periods $173 / 01$ to $213 / 01$ and $213 / 01$ to $253 / 01$ ) reveal the pres- ence of a cyclonic structure (C6) close to meddy M6, the latter drifting northeastwards at an average speed of $0.025 \mathrm{~ms}^{-1}$ during that period. In the last time frame shown the meddy practically stalled with a drift below $0.01 \mathrm{~ms}^{-1}$.

\subsubsection{Surface tracer patterns}

Remote measurements are crucial in this case to reconstruct the eddy field and explain the movement of meddy M6. Figure 7 shows a sequence of SST maps, from 1 April 2001 (91/01) to 5 August 2001 (217/01), that allows the detection at the surface of the dipole from which M6 was the anticyclonic component. The SST image from 1 April 2001 (91/01) shows that meddy M5 was moving around the anticyclonic part of a mushroom-like pattern which was the surface expression of an underwater dipole. In the second image (Fig. 7b), the large loop described by the float is centred with the western part of the SST pattern. This is a clear demonstration that meddy M5 merged with the pre-existing meddy M6. The following 3 images (from mid-May 2001 to mid-June 2001) all show the dipole moving in a southeast direction. It is interesting to notice that, as before in the case of the CANIGO dipole M4-C4 (Fig. 3), the cyclonic part of the dipole is more evident and more symmetric.

Meddy M7 does not have a clear surface signature, whereas cyclone $\mathrm{C} 7$ shows up as a pool of warm water surrounded by a thin band of cold water in the image from 18 June 2001 (Fig. 7f). The cyclone seems to extend from an upwelling filament rooted at Cape St. Vincent. If this cyclone was generated by the overshoot of the upwelling related current, then these results prove that upwelling phenomena could greatly interact with the MW Undercurrent. In the last 3 images of the sequence cyclone C6 keeps its position (around $35^{\circ} \mathrm{N}, 9^{\circ} \mathrm{W}$ ) and meddy M6 is forced to move around the cyclone, thus explaining the re-circulation of M6 in the Gulf of Cadiz.

A sequence of chl- $a$ concentration distributions from 18 January 2001 (49/98) to 5 August 2001 (217/01) is presented in Fig. 8. The first image in the sequence shows a circular pattern centered at $36^{\circ} \mathrm{N}, 10^{\circ} \mathrm{W}$. Some pigments in the centre of the pattern disclose an anticyclonic movement, which is compatible with the float displacements at depth. It is the surface expression of meddy M6. The next image from 31 March 2001 (Fig. 8b) shows a maximum in chlorophyll concentration attached to the cyclonic part of a mushroom feature near $36^{\circ} \mathrm{N}, 9^{\circ} \mathrm{W}$. These pigments were captured in the filament extending south from Cape St. Vincent. In the next 3 images, the mushroom-like pattern, corresponding to dipole C6-M6, is clearly seen although the signal is gradually fading. In the image from 5 August 2001 (Fig. 8h) the cyclone no longer presents an accumulation of chlorophyll. It is outstanding, however, the persistence of this accumulation in C6 at great distances from the slope, lasting more than 3 months. 

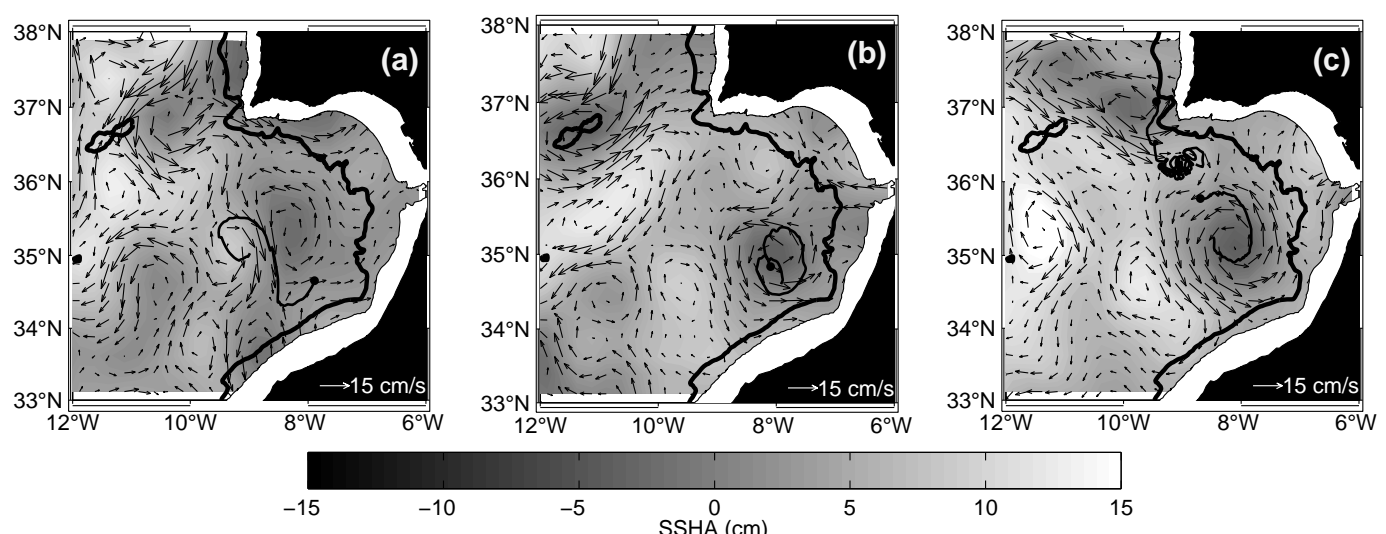

Fig. 5. SSHA maps from (a) 13 July 1998 (194/98) (b) 12 August 1998 (224/98) and (c) 1 October 1998 (274/98) with the relative geostrophic velocity vectors superimposed. Selected RAFOS trajectories (image date \pm 5 days) are also overlaid (depth ranges from $700 \mathrm{~m}$ to $1300 \mathrm{~m}$; the dot corresponds to the last float position in the period). The black thick line is the 1000-m depth contour.
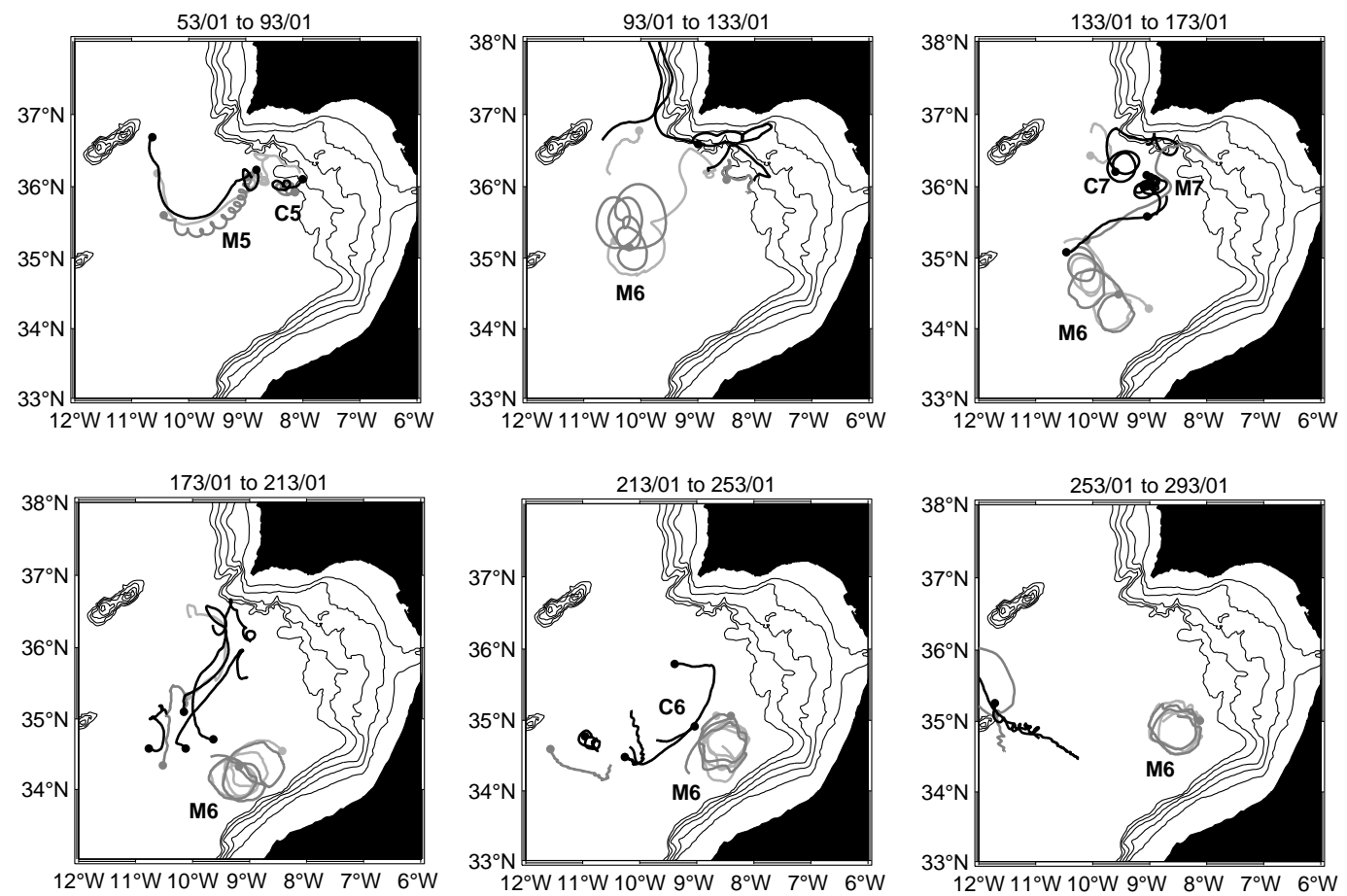

Fig. 6. Selected MEDTOP float trajectories segmented in periods of 40 days from 22 February 2001 (53/01) to 20 October 2001 (293/01) showing the movement of a meddy around a cyclone in the Gulf of Cadiz. Black trajectories correspond to floats operating at depths between $700 \mathrm{~m}$ and $1000 \mathrm{~m}$ and grey trajectories to floats drifting between $1000 \mathrm{~m}$ and $1300 \mathrm{~m}$ (the dot corresponds to the float last position in the shown period). Label M refers to meddies and label C to cyclones. Bathymetry is contoured from 200-m to 1800-m depth with a spacing of $400 \mathrm{~m}$.

\subsubsection{Surface dynamical field}

Altimetry results corroborate the existence of both meddy M6 and cyclone C6 and their interaction (Fig. 9). The SSHA map from 21 March 2001 (80/01) demonstrates the existence of an anticyclone (positive anomaly) at $36^{\circ} \mathrm{N}, 10^{\circ} \mathrm{W}$, along which the float within the smaller meddy M5 moves. Cy- clone $\mathrm{C} 6$ is present in subsequent maps as a strong negative SSHA, values lower than $-10 \mathrm{~cm}$. Figure $9 \mathrm{~b}$ indicates velocities in the cyclone higher in the northern and southwestern sides, where the interaction with meddies M6 and M7 is evident. In the last SSHA distribution of the sequence, from 18 August 2001 (230/01), cyclone C6 becomes more elongated 


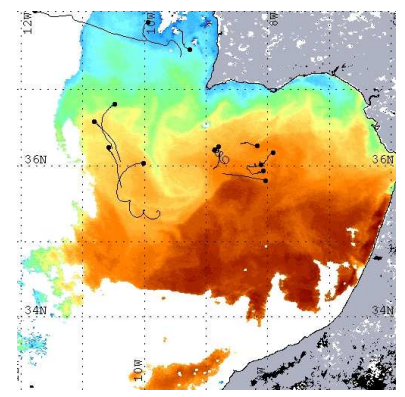

(a)

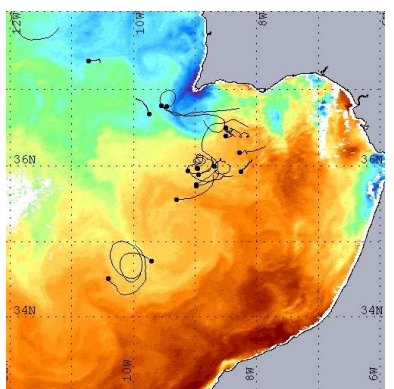

(d)

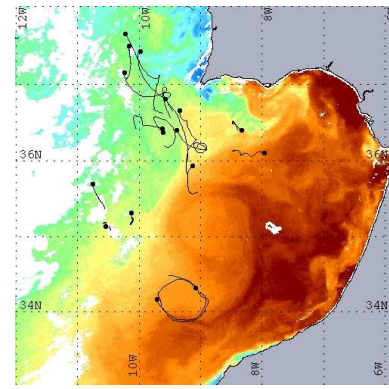

(g)

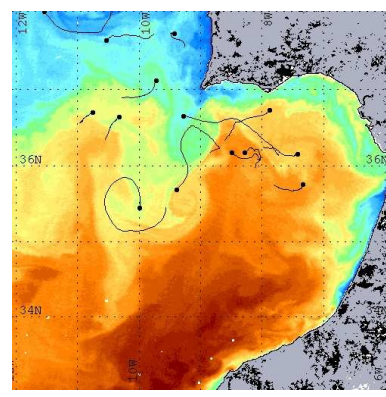

(b)

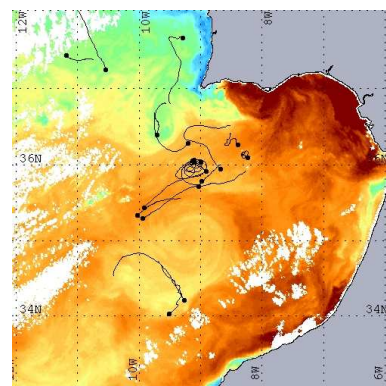

(e)

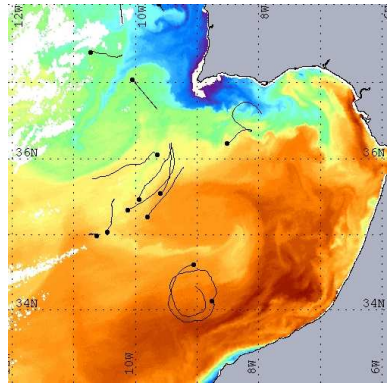

(h)

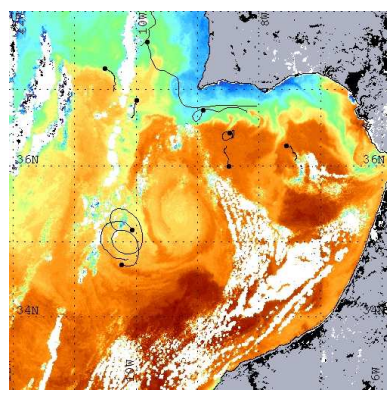

(c)

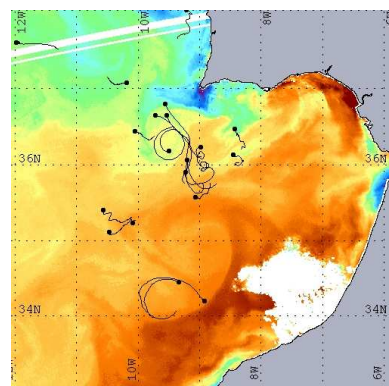

(f)

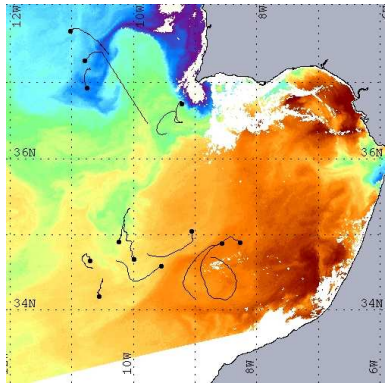

(i)

Fig. 7. SST images showing the surface signature of the dipolar structure found during MEDTOP for (a) 1 April 2001 (91/01), (b) 15 April 2001 (105/01), (c) 11 May 2001 (131/01), (d) 25 May 2001 (145/01), (e) 5 June 2001 (156/01), (f) 18 June 2001 (169/01), (g) 28 June 2001 (179/01), (h) 16 July 2001 (197/01) and (i) 5 August 2001 (217/01). Underwater float trajectories (image date \pm 5 days) are superimposed (depth ranges from $700 \mathrm{~m}$ to $1300 \mathrm{~m}$; the dot corresponds to the float last position). The colorbar is not presented since values are irrelevant for the pattern identification (blue tones correspond to cold water and orange/red tones to warm water).

and the intensification of velocity is still present in the region between $\mathrm{C} 6$ and M6.

\section{MW dipoles in a numerical simulation and their impact on the upper ocean}

In this section we turn attention to the numerical simulations and focus on the impact of MW dipoles in the upper ocean, their vertical structure and on the contribution of meddies for the zonal volume and salt transport in the MW layers.

\subsection{Relation between model MW properties and surface variables}

Figure 10a shows a snapshot of model salinity at $1100 \mathrm{~m}$ in 15 September during the fifth year of model integration (corresponding to year 1994 of surface forcing). A pool of high salinity water is present offshore from the western Iberian coast, populated with approximately 18 meddies containing in their cores the most undiluted MW. Due to the high resolution employed, the internal deformation radius within the MW Undercurrent (estimated to be about $10 \mathrm{~km}$ based on in situ measurements (Serra, 2004) is resolved, leading to an enhanced realism of the simulations. Furthermore, the high horizontal and, in particular, the high vertical resolution allows a better representation of velocity shear around the 
MW Undercurrent, important for the eddy generation. Superimposed to the salinity distribution are 11 (selected out of 900) trajectories of isobaric floats deployed in the model on the above mentioned date (deployment depth is $1100 \mathrm{~m}$; trajectory length is 290 days). In agreement with observations (Bower et al., 1997; Richardson et al., 2000), a clear tendency for meddies to translate to the southwest can be noticed. The sudden stall and turn of the tagged meddies, as suggested by the floats evolution (also seen in observations), is entirely due to interaction with other eddies, this being concluded from an animation of model properties (not shown). The MW thickness during the same day is illustrated in Fig. 10b. The material surface $S=36.1$ is used to define the layer. Meddies have core thickness ranging from $650 \mathrm{~m}$ up to $850 \mathrm{~m}$ and are embedded in a layer $400-500 \mathrm{~m}$ thick. It can be noticed that, according to the above definition, the MW layer high salinity is confined to the region east of $16^{\circ} \mathrm{W}$, with only meddies carrying the MW high-salinity signal westward from that longitude. Coinciding with that longitude, the float trajectories show a tendency for an increase in the meridional component of the meddy drift.

In order to characterize the rotation in these eddies found in the salinity distribution, the model relative vorticity was averaged in the layer $800-1200 \mathrm{~m}$ (Fig. 11b). Relative vorticity is here presented as a fraction of the planetary vorticity and the ratio can be taken as a vorticity-based equivalent of the Rossby number. The turbulent nature of the MW flow can be readily seen. Large negative vorticity poles (anticyclonic rotation) coincide with the high salinity cores, with the average core vorticity being well in agreement with estimates derived from in situ float observations (Bower et al., 1997; Serra et al., 2002). The source of vorticity for the MW eddies is the boundary undercurrent. The agreement thus implies a good representation of horizontal shear in the MW Undercurrent and realistic levels of friction at the slope, fact that is not granted solely by the high-resolution, since numerical models use constant background horizontal viscosity. In the present case, the use of biharmonic diffusion/viscosity seems to be beneficial.

Positive vorticity patches are also ubiquitous around meddies and in some instances allow the identification of cyclonic counterparts to some of them. The largest negative vorticity signal is confined to the MW layer. However, positive vorticities do not show maxima at the same level of meddies. Figure 11a presents the normalized relative vorticity, for the same time step, averaged in the layer $100-500 \mathrm{~m}$, well above the MW layer. As expected, the upper ocean is more energetic and it is clear that cyclonic vortices have their vorticity peaking in the layer above the MW. In all the cases of meddies identified in Fig. 10a, Fig. 11 points to companion cyclones being more intense in the layer $100-500 \mathrm{~m}$ (see for instance the dipole centred at $36^{\circ} \mathrm{N}, 13^{\circ} \mathrm{W}$ ).

Before addressing the vertical structure of model MW dipoles, the model SST and SSH from the same day are analysed (Fig. 12). The model SST is the temperature at

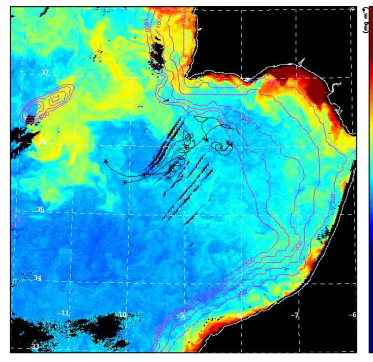

(a)

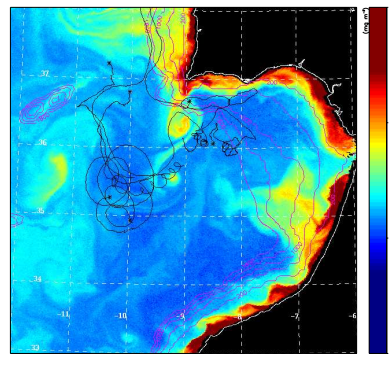

(c)

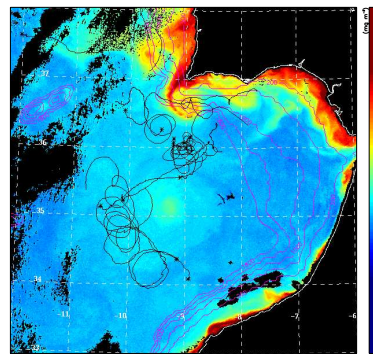

(e)

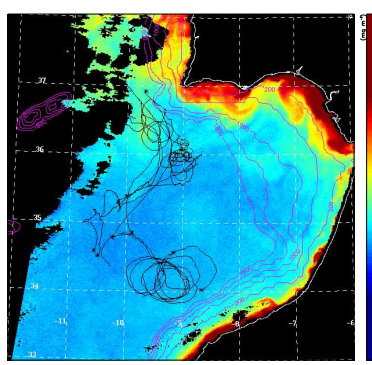

(g)

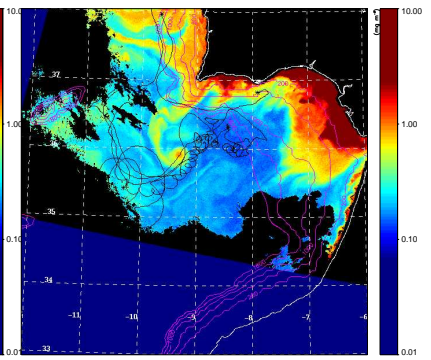

(b)

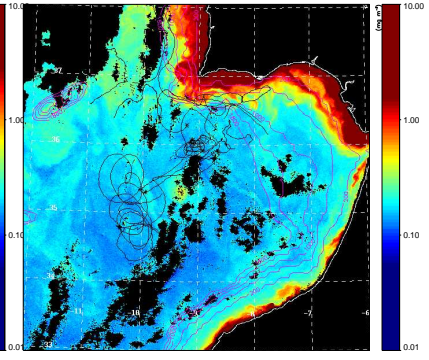

(d)

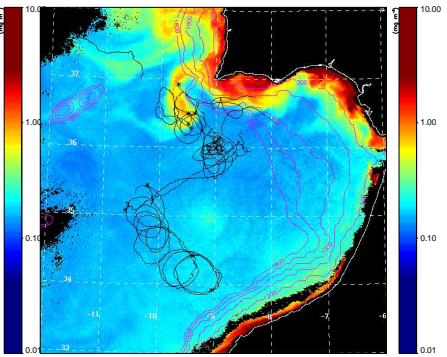

(f)

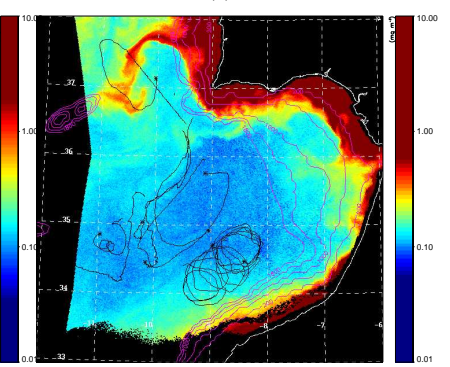

(h)
Fig. 8. Chlorophyll- $a$ concentration distributions (units: $\mathrm{mgm}^{-3}$ ) in (a) 18 February 2001 (49/01), (b) 31 March 2001 (90/01), (c) 14 April 2001 (104/01), (d) 11 May 2001 (131/01), (e) 25 May 2001 (145/01), (f) 6 June 2001 (157/01), (g) 28 June 2001 (179/01) and (h) 5 August 2001 (217/01), showing the surface expression of the MEDTOP dipole. Selected MEDTOP float trajectories are overlaid.

$2.5 \mathrm{~m}$ (mid-depth of layer 1), so in fact it is more related to bulk SST rather than to skin SST measured by the satellite sensors, the latter being more directly affected by highvariability air-sea fluxes. The distribution from late summer shows a band of cold water against the coast, revealing the occurrence of upwelling in the model. A thorough 


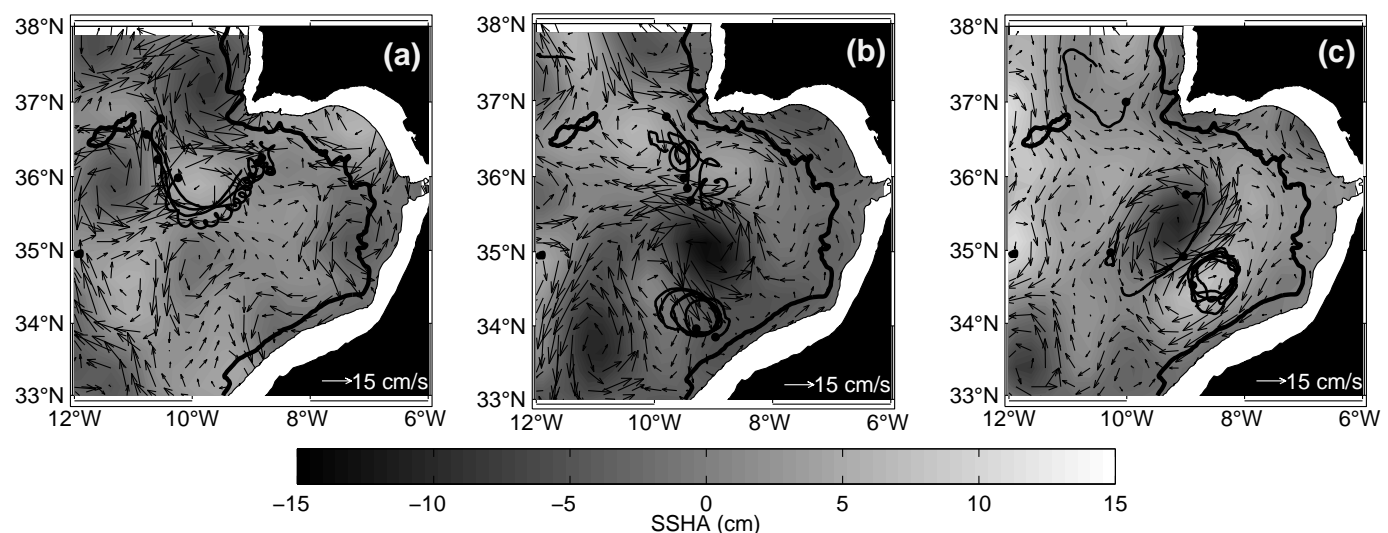

Fig. 9. SSHA maps from (a) 21 March 2001 (80/01) (b) 29 June 2001 (180/01) and (c) 18 August 2001 (230/01) with the relative geostrophic velocity vectors superimposed. Selected RAFOS trajectories (image date \pm 5 days) are also superimposed (depth ranges from $700 \mathrm{~m}$ to $1300 \mathrm{~m}$; the dot corresponds to the last position). The black thick line is the 1000-m depth contour.

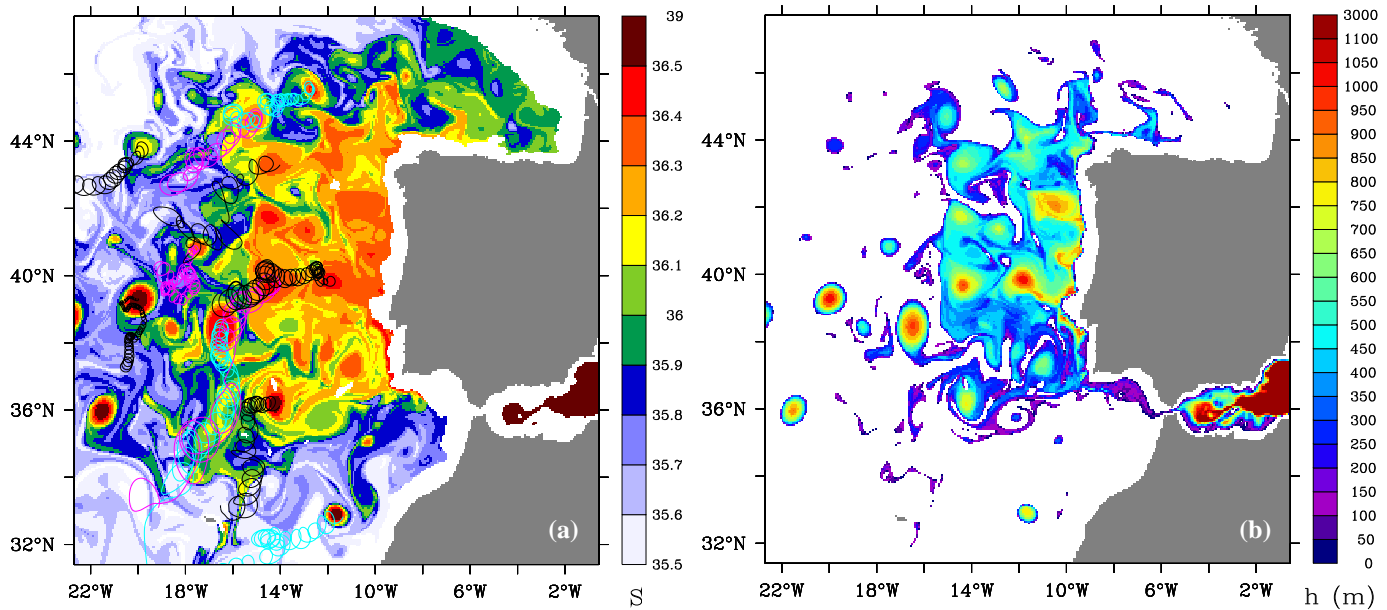

Fig. 10. Instantaneous distribution from mid-September (year 5) of model (a) salinity at $1100 \mathrm{~m}$ and (b) MW layer thickness (MW defined as water with $S>36.1$ ). Selected trajectories (duration: 9 months) of model floats deployed within meddies at the shown time are superimposed in (a).
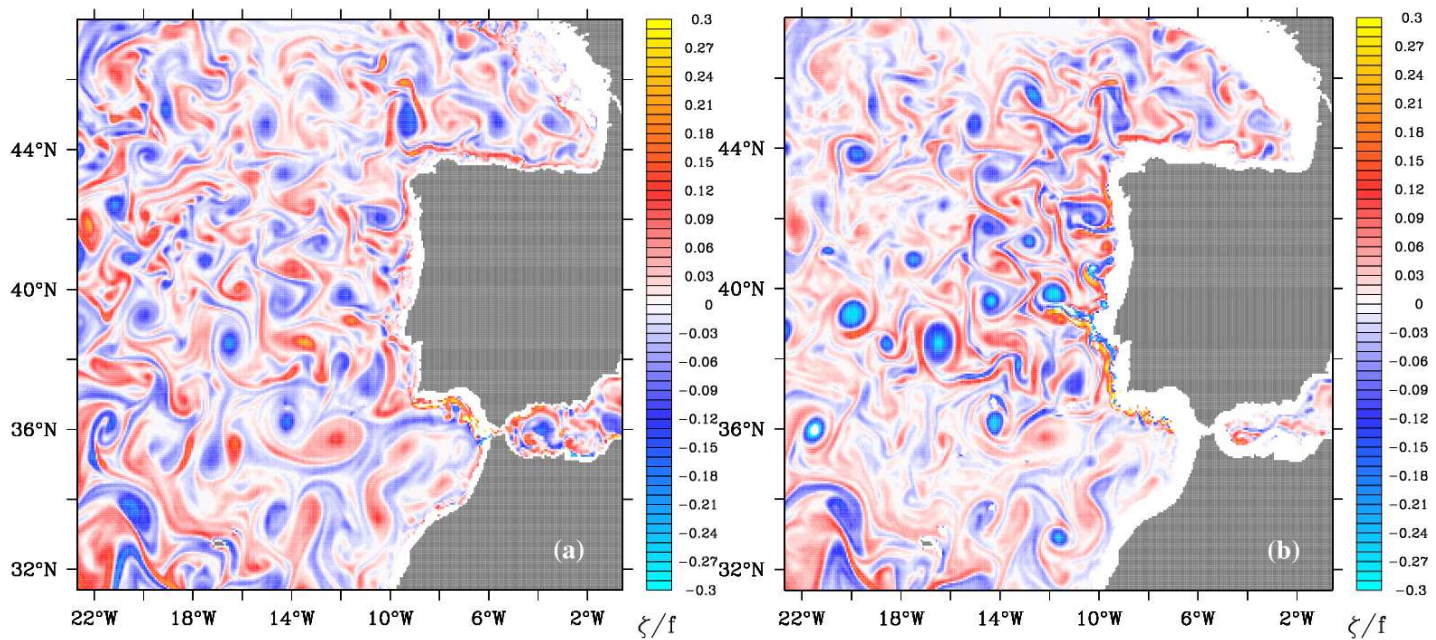

Fig. 11. Instantaneous distribution from mid-September (year 5) of model relative vorticity (normalized by the planetary vorticity $f$ ) averaged in the layers: (a) 100-500 $\mathrm{m}$ and (b) 800-1200 m. 


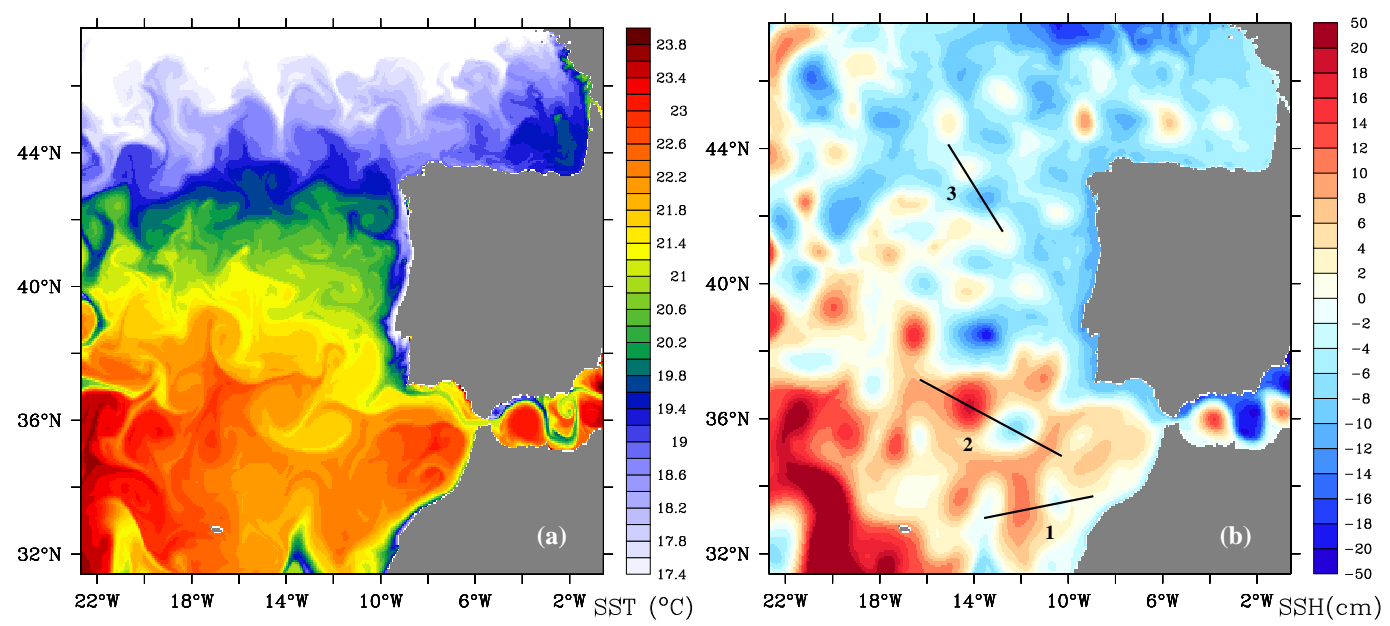

Fig. 12. Instantaneous distribution from mid-September (year 5) of model (a) sea surface temperature and (b) sea surface height. Black lines in (b) correspond to the locations of vertical sections shown in Fig. 13.

comparison of the SST distribution with observations is here out of scope. It is however interesting to notice the good agreement (despite the coarse horizontal resolution of the NCEP wind forcing) with certain features seen in Figs. 3 and 7, namely the extension of upwelling filaments from Cape St. Vincent (see the observational study of Sanchez et al., 2008) and in particular the long filament directed towards the Strait of Gibraltar (compare with Figs. 3f and 7b).

There is a considerable interaction between the MWinfluenced layers and the surface. The development of the southwestward-extending upwelling filament seen in the model at $\left(37^{\circ} \mathrm{N}, 10^{\circ} \mathrm{W}\right)$ is fully determined by the presence north of the filament, at $\left(37.3^{\circ} \mathrm{N}, 11^{\circ} \mathrm{W}\right)$, of a meddy recently shed from Cape St. Vincent (compare with Fig. 10a, b). The meddy negative vorticity pole can be seen both in the layer $800-1200 \mathrm{~m}$ and in the layer $100-500 \mathrm{~m}$ (Fig. 11). On the other hand, the upper ocean vorticity shows a positive patch corresponding to a cyclone that is forming and interacting with the meddy. The filament is located precisely between the two vortices, a region of enhanced velocity, large enough to capture water (with its properties) from the shelf and advect it into the open ocean. The same process occurred with the filament rooted at $\left(39.5^{\circ} \mathrm{N}, 11^{\circ} \mathrm{W}-\right.$ Fig. 12a). A meddy shed from the MW Undercurrent at the Estremadura Promontory can be found north of the filament (Fig. 10a). The latter curled clockwise at the meddy offshore edge.

The most prominent feature in the SST distribution is, however, the mushroom-like pattern centred at $\left(36^{\circ} \mathrm{N}\right.$, $13^{\circ} \mathrm{W}$ ), which has a close correspondence in the salinity and vorticity distributions. Interestingly, temperatures within the cyclonic counterpart are lower, thus revealing that the cold water which is extracted from the coastal zone in between the positive and negative poles is mainly directed to the cyclonic counterpart. This fact is due to the cyclone being a shal- lower and surface intensified structure. The above examples show that the presence of MW eddies is responsible for the large offshore excursion of some of the upwelling filaments generated in the area and that these have no need for strong wind forcing. Although considered as a typical summer phenomenon, wind-induced upwelling along the Portuguese coast can occur sporadically in winter (Fiúza, 1982; Haynes et al., 1993; Santos et al., 2004). The winter development of an extremely long filament (about $400 \mathrm{~km}$ ) off the Portuguese west coast, as reported by Peliz et al. (2004) using satellite data, could not be related to wind-driven dynamics since the winds were from southwest. The authors detected this filament rooted off Cape St. Vincent and extending southwestwards with Chl- $a$ pigment concentrations of about one order of magnitude larger than the values of the surrounding waters. The analysis of contemporaneous images of SST and SSH anomaly showed the presence of eddy structures (two anticyclones and one cyclone) interacting in the region of the filament. The authors estimated the Lagrangian trajectories associated with the surface wind (Ekman velocity) and with the geostrophic velocity field derived from the SSH anomaly. They concluded that a better match to the observations was obtained using only the geostrophic field and that the wind had little influence on the generation and stretching of the filament.

The SSH for the same model day (Fig. 12b) shows an overall northeast-southwest gradient corresponding to the background circulation in the region, with the Azores Current entering the domain in the south and the depression at the coast being related to the upwelling-induced coastal divergence and southward current. All meddies identified in Fig. 10b have a corresponding positive SSH anomaly in Fig. 12b, confirming once again the altimetric signal of meddies (Stammer et al., 1991; Oliveira et al., 2000). There are however other positive anomalies that are related to eddies shed from 

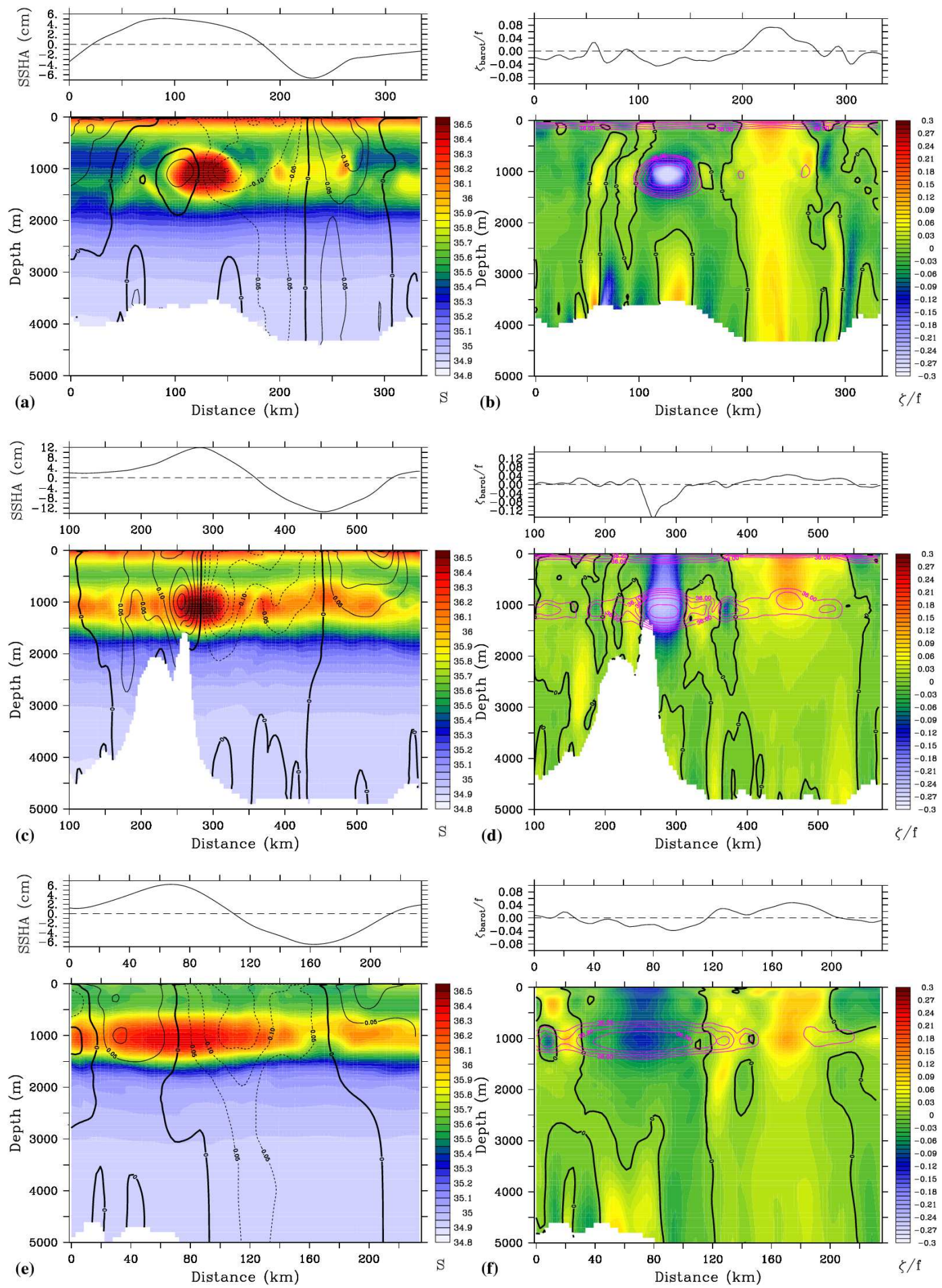

Fig. 13. Vertical sections across three selected MW dipoles generated in the model (Fig. 12b, Sect. 1 - top row; Sect. 2 - middle row; Sect. 3 - bottom row): (a, c, e - top panels) sea surface height anomaly; (a, c, e - bottom panels) salinity and meridional component of velocity; (b, d, f - top panels) normalized barotropic vorticity; (b, d, f - bottom panels) normalized relative vorticity and salinity larger than 36.

the Azores Current or from the North Atlantic Current. So, in fact, some ambiguity is present when relying only on altimetry to locate meddies. When comparing the SSH and the vorticity distributions, it can be seen that the former field presents broader scale patterns and that a one-to-one correspondence is not always easily established. 


\subsection{Vertical structure of simulated dipoles}

The attribution of model SSH variability to meddy-induced fluctuations will be shown later in Sect. 4.4. We focus first on the vertical structure of MW dipoles. Figure 13 presents the vertical structure of three dipoles generated in the model, corresponding to Sects. 1-3 shown in Fig. 12b. Salinity vertical distributions are presented in the lower panels of Fig. 13a, c, e with the velocity component perpendicular to the section superimposed (meridional component in cases 1-2 and zonal component in case 3), whereas the upper panels depict the SSH anomaly. The relative vorticity (normalized by the planetary vorticity) distributions for the same sections are in the lower panels of Fig. 13b, d, f and the barotropic vorticity in the upper panels.

First of all, the realistic penetration depth of the MW in our simulations can be appreciated. In all the examples, the anticyclone contains the majority of the MW salinity signal, whereas the cyclone comprises less salty or ambient water. This is also clear in Fig. 10a, which shows filaments of high salinity water wrapped around the centre of the cyclones. Meddy velocities are intensified in the MW layer, with the larger negative vorticities being found there. The negative vorticity extends to the surface in all 3 cases, especially in the two northernmost ones, which are closer in space and time to their generation. In the deeper layers below the three meddies, an inversion in vorticity sign is present. On the other hand, an interesting feature is the top-to-bottom extension of the cyclone, as can be seen in the velocity within these poles or in the positive vorticity regions east from the meddies. The cyclone has thus a tendency to be more barotropic than the anticyclone. The depths of maximum azimuthal velocities within the model cyclones do not coincide with those of the anticylones and are located at the layers above the MW (in case 1 a bottom intensification can be seen as well). This is an indication that the cyclone has been formed initially at shallower depths and then spread its influence throughout the water column. This is also consistent with the fact of the MW Undercurrent being bounded by regions of positive shear (particularly strong above the MW), which are source for the cyclones.

SSH anomalies in the three dipoles have similar magnitudes to those shown in Figs. 5 and 9. In a depth-integrated sense (see barotropic vorticity), the dipoles ejected from the MW Undercurrent act as barotropic modons, but they were shown here to have a baroclinic (hetonic) structure. We conclude that the dipoles generated in the model have characteristics compatible to those observed at the same locations during the CANIGO and MEDTOP projects (Serra et al., 2005; Ambar et al., 2008), so that the present simulations offer the possibility of studying the complex meddy evolution from birth and cyclone-anticyclone coupling to interaction with topography and dissipation.


Fig. 14. (a) Meridionally integrated volume (black - units: Sv) and salt (red - units: Svpsu) zonal transports in the MW layer (volume and salt transports share the same axis). Dashed lines correspond to the case in which only meddy contributions (see text) are accounted. (b) Ratio between meddy ( $T_{\text {meddy }}$ ) and total ( $T$ ) volume (black) and salt (red) zonal transports.

\subsection{Estimate of meddy contribution to volume and salt transport}

South of Cape St. Vincent the MW Undercurrent volume transport amounts to about 3.5 Sv (Ambar and Howe, 1979; Ochoa and Bray, 1991) and the salt transport to about 1 Svpsu. From there onwards, MW is transported to the north within the slope undercurrent and to the west partly within meddies. An estimate of the individual contribution of meddies to the overall westward transport in the MW layer was conducted. The MW layer is defined, as above, as water below $300 \mathrm{~m}$ with salinity larger than 36.1 . At each location, a layer-integrated volume and salt flux was computed and then meridionally integrated at each longitude. Figure 14a shows the resulting net zonal volume (solid black line) and salt (solid red line) transports. A general westward decrease in transports can be seen, consistent with signal erosion through mixing. In order to isolate the meddy contribution to these transports, the same computation was performed with the extra criteria of relative vorticity at each position being negative (actually less than $-0.01 f$ ), this way accounting only the fluxes in salty and clockwise-rotating lenses. The dashed lines in Fig. 14a show this result and the ratios between the meddy-only and the total transports are depicted in Fig. 14b. East of $16^{\circ} \mathrm{W}$ the meddy contribution is $20-40 \%$ for the total zonal volume transport and 30-50\% for the total zonal salt transport. Between $16^{\circ} \mathrm{W}$ and $18^{\circ} \mathrm{W}$ the meddy contribution increases to $50 \%$ and $70 \%$ for volume and salt transports, respectively. This coincides to the region where eddies are more spread out, interacting less between them 

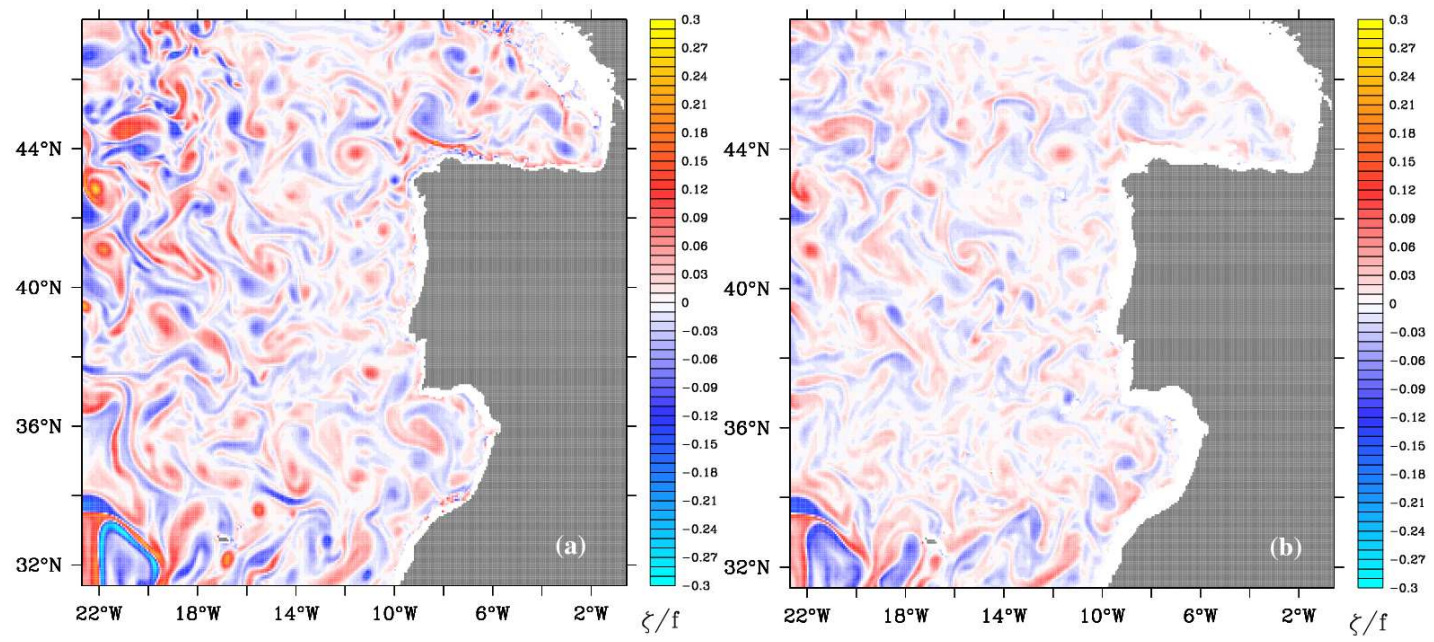

Fig. 15. Same as Fig. 11 but for the model simulation case without MW outflow and meddies (see text).

and becoming more isolated features. East of $16^{\circ} \mathrm{W}$, meddies are closer to their generation sites and the population is large. The promoted eddy interaction and dipole formation there leads, on one hand, to enhanced advection of MW from the slope into the Iberian Basin and, on the other hand, to large levels of eddy stirring and mixing. In our opinion, even if meddies do not account directly to the total volume and salt transports, they do so indirectly through advection. In the far west, meddies do account directly to the majority of transports. The tendency they show, when isolated, to move to the southwest explains the well-known southwestward elongation characteristic of the MW salinity tongue.

A quantification of meddy contribution to the westward salt and volume transports depends highly on the realism of the simulation concerning meddy population. The latter is determined on one hand by the presence of several generation sites along the western Iberian continental slope (Portimao Canyon, Cape St. Vincent, Estremadura Promontory and Cape Finisterre), each of which shown in published works to have different associated mechanisms (boundary current barotropic/baroclinic instability and/or current separation at topographic features). On the other hand, the meddy population at a certain instant depends on the frequency of formation at each generation site, but this is intrinsically determined by the generation mechanism (meddies take some time to form at each site depending on flow parameters and regimes and when they detach a new generation event is possible). Finally, the population in a given volume also depends on meddy interactions with other eddies and topography (which might lead to meddy disruption) and on meddy movement (self-propagation, eddy interactions and background mean current advection). Given all of the above, it is possible that our simulations might fail in one or other aspect, leading to uncertainty in the above estimates of meddy contribution.
Bower et al. (1997) estimated a formation frequency of about 17 meddies per year (Cape St. Vincent and Estremadura Promontory together) based on subsurface float trajectories and gave valuable kinematic properties of meddies against which we compared our simulated meddies. Richardson et al. (2000) pointed to a meddy population in the Iberian Basin (south of $43^{\circ} \mathrm{N}$ ) of about 11 meddies during 1994, but it is not known if all the population was sampled. During the model instant shown previously about 20 meddies can be counted, thus close to the observations if one takes into account that our study area encloses one more generation site - Cape Finisterre. An estimate of the complete meddy population based on remote sensing data seems unachievable since not all meddies have clear surface expression (in particular when they are away from the coastal region) and remote measurements do not have adequate spatial and temporal resolutions (due to mission characteristics and/or cloud cover). Since our domain includes all (according to current knowledge) of the Iberian generation sites and our model is successful (partly due to the high horizontal/vertical resolution) in simulating key aspects of the MW undercurrent (for instance its penetration level, thickness and salinity maxima), it is assumed that the undercurrent dynamics are well represented and that realistic generation mechanisms occur in the model, leading to realistic formation frequencies. Simulated meddies have dimensions and peak vorticities comparable to those reported in the literature. Furthermore, eddy interactions (and dipole formation), as shown before to be comparable to remote sensing patterns, assure the realism in meddy propagation out of the coastal region. It is thus concluded that our estimates of meddy fluxes have some realism, however, a proper validation is not possible. 

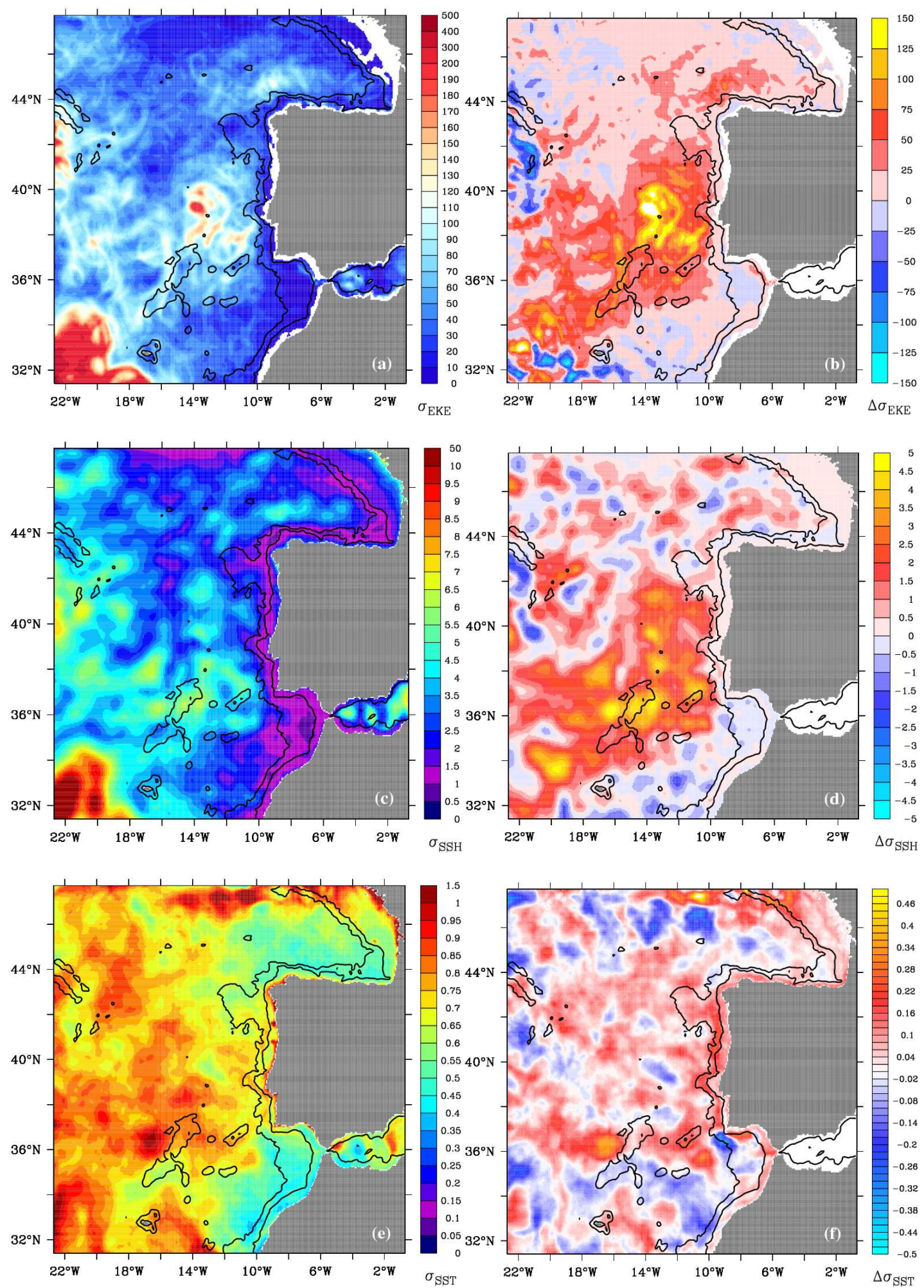

Fig. 16. Standard deviation of (a) 100-500 $\mathrm{m}$ averaged eddy kinetic energy $\left(\mathrm{cm}^{2} \mathrm{~s}^{-2}\right)$, (c) sea surface height (cm) and (e) sea surface temperature $\left({ }^{\circ} \mathrm{C}\right)$. (b, d, f) show the differences to the corresponding standard deviations in the model run without MW outflow and meddies. The bathymetric lines correspond to $500 \mathrm{~m}$ and $3000 \mathrm{~m}$ depth. 


\subsection{Impact of MW eddies in the upper ocean variability: a sensitivity experiment}

We continue to analyse the impact of meddies and meddyinduced circulation on the variability of the upper ocean offshore from the Iberian Peninsula. The simplest way of getting the full response is not allowing the overflow of MW into the Gulf of Cadiz and consequently no eddy formation at mid-depth. A sensitivity experiment was thus conducted in which the Strait of Gibraltar was closed and the Mediterranean Sea excluded from the computations. All model parameters, initial and boundary conditions and forcing were maintained, including the length of the run.

In Fig. 15, the same layer-averaged vorticity fields as in Fig. 11 are presented. From the comparison of Figs. 11b and $15 \mathrm{~b}$, a clear reduction in vorticity at the MW layer is visible, as expected, since eddy formation no longer takes place. Although positive and negative vortices still exist (a remnant of MW from the initial condition is still present), strong eddies can no longer be seen. The lack of MW eddies impacts the upper ocean as well, as can be noticed in the upper layer $(100-500 \mathrm{~m})$ vorticity (Fig. 15a). Comparing Figs. 11a and $15 \mathrm{a}$, a reduction in vorticity magnitude (and also on the size of positive/negative patches) again occurs in the region closer to the Iberian coast. Offshore, in the west and south, similar vorticity levels are present in both runs, resulting from instabilities of the currents inflowing into the domain (Azores Current and North Atlantic Current extension).

The eddy kinetic energy (EKE) variability in the layer above the MW from the realistic run is shown in Fig. 16a. Besides the two offshore regions of high EKE near the boundaries, the distribution shows values larger than $100 \mathrm{~cm}^{2} \mathrm{~s}^{-2}$ in the Iberian Basin, from $36^{\circ} \mathrm{N}$ to $42^{\circ} \mathrm{N}$ and $10^{\circ} \mathrm{W}$ to $16^{\circ} \mathrm{W}$, where meddies are recently shed from Cape St. Vincent and Estremadura Promontory and closely interact. Figure 16b shows the difference in EKE between the realistic run and the sensitivity run without MW outflow and meddies. A dramatic reduction of energy levels and thus of eddy-induced mixing can be seen in the Iberian Basin, extending southwestwards towards the Canary Basin. As expected, this region coincides with what was seen in the relative vorticity.

Since, as shown before, eddies have a clear signal in SSH, its variability should be also affected in the run without MW outflow. Figure 16c shows the standard deviation of SSH after removing the seasonal cycle. The slope region shows low values of SSH variability (below $2 \mathrm{~cm}$ ), the highest EKE region $(>7 \mathrm{~cm})$ is again linked to the Azores Current and moderate values can be found in the Iberian Basin and, in particular, over the variable topography of the Horseshoe chain of seamounts, with which many meddies are known to interact and, eventually, be disrupted (Richardson et al., 2000). The run without MW outflow presents lower values of SSH variability (up to $5 \mathrm{~cm}$ ), as can be seen by the positive differences in standard deviation (Fig. 16d). The anomalous region highly coincides with the corresponding positive anomaly area seen in the layer-averaged EKE. Although three years are definitely not enough to derive significant statistics, we believe the obtained pattern is robust. We thus here conclude that meddies are of determining importance to set the upper layer variability in the Iberian Basin. More interestingly, the same investigation was conducted for the non-seasonal SST variability (Fig. 16e). The standard deviation of the realistic run shows the Gulfs of Cadiz and Biscay as regions of low variability (below $0.5^{\circ} \mathrm{C}$ ) and variability of up to $1^{\circ} \mathrm{C}$ can be found offshore. The pattern of the difference is now quite distinct from that of SSH and EKE. In fact, positive anomalies are found onshore from the 3000-m isobath, fact that is attributed here to the meddy/dipole-induced impact on the upwelling regime, by extracting cold upwelled water from the coast within highly extended filaments. Further offshore, from $36^{\circ} \mathrm{N}$ up to $44^{\circ} \mathrm{N}$, mainly positive anomalies can be seen, leading to the conclusion that eddies can have an impact on the SST variability of the Northeast Atlantic. Since eddies change the SST, the heat fluxes will also be changed, so we expect part of the difference between both runs to be related to modified air-sea exchange.

\section{Summary of conclusions}

Surface filaments and eddies are known to be key factors in the transfer processes of mass, heat and momentum between the shelf and the deep ocean. The ability of eddies to transport and disperse dynamically passive (dissolved or suspended) materials can have far-reaching effects on the chemical and biological characteristics of the deep ocean. In the last decade, field observations off the southern coast of Iberia were able to detect the presence of cyclones associated with meddies to form vortex pairs (dipoles) at the level of the MW. The dynamical fields associated with meddies and cyclones extend vertically much farther than the depth range where the thermohaline anomaly is detected, and may reach levels down to $3000 \mathrm{~m}$ or up to the sea surface. The implications of such an extensive dynamical field in the shelf-deep ocean exchanges were here presented.

The comparison between float trajectories and the distribution of two scalar fields - SST and chl- $a$ concentration - acting as passive tracers of the movement in the surface layers, showed that the surface expression of MW dipoles could be assessed by remote measurements. The mushroomlike surface patterns associated with the dipoles result from the wrapping of thermal and chlorophyll concentration gradients around the vortical structures. One general result is the more clear identification of the cyclonic counterparts of the dipoles, thus indicating that the cyclone is more intense at shallower depths than the anticyclone and pointing to a baroclinic character of the dipolar structure as a whole.

Furthermore, the altimetric signal of MW dipoles could also be reconstructed. On the other hand, their clear 
identification with altimetry imprints a barotropic character to the currents in the dipoles. The fact that the cyclones could be identified for longer times at the surface is an indication of the barotropicity in cyclones or evidence of them being surface intensified features, whereas meddies are clearly middepth intensified. This fact is related to the differences in the generation, in the sense that the cyclones tend to be formed at shallower depths than the anticyclone. The altimetry results reinforce this fact since the SSH (or its anomaly) is somehow a depth-integrated quantity, giving the barotropic part of the water column velocity. So, even if the cyclone is weaker in strength, if it comprises more of the water column, it will show up strongly at the surface.

A numerical model simulation forced by realistic atmosphere-ocean exchange confirmed here the vertical structure of MW dipoles, the link between the MW layer circulation and the upper ocean and in particular the impact on SSH and SST. Our observational and model results also indicated that some of the filaments (most certainly those that extend further offshore) that are frequently observed in the Portuguese coastal upwelling region are due to the presence of MW meddies and cyclones. The dipolar system is able to transport chlorophyll pigments away from the coastal region for large periods of time (order of few months) before decaying or being destroyed by topography. This has important implications for the removal of high productivity waters from the coastal region.

Acknowledgements. This work was funded by the Portuguese Fundacao para a Ciencia e Tecnologia (FCT) projects RENA (Contract PDCTE/CTA/49945/2003), MUD (Contract POCI/MAR/58384/2004) and SATMAR (Contract REEQ/1136/MAR/2005). The float data was acquired during the CANIGO project, supported by the EU MAST-3 programme (Contract MAS3-CT96-0060), and during the FCT project MEDTOP (Contract PDCTM/P/MAR/15301/1999). The SeaWiFS data is a courtesy of the NASA SeaWiFS Project and the Orbital Sciences Corporation. The altimeter products were produced by the CLS Space Oceanography Division, Toulouse, France, as part of the EU Environment and Climate project AGORA (Contract ENV4-CT9560113) and DUACS (ENV4-CT96-0357). The authors aknowledge the computer resources and technical assistance provided by the Barcelona Supercomputer Center Centro Nacional de Supercomputacion.

Edited by: J. A. Johnson

\section{References}

Afansyev, Y., Kostianoy, A., Zatsepin, A., and coauthors: Analysis of velocity field in the eastern Black Sea from satellite data during the Black Sea 1999 experiment, J. Geophys. Res., 107(C8), 3098, doi:10.1029/2000JC000578, 2002.

Ambar, I. and Howe, M.: Observations of the Mediterranean outflow - I: Mixing in the Mediterranean outflow, Deep-Sea Res., 26, 535-554, 1979.
Ambar, I., Serra, N., Neves, F., and Ferreira, T.: Observations of the Mediterranean Undercurrent and eddies in the Gulf of Cadiz during 2001, J. Mar. Sys., 71, 195-220, 2008.

Armi, L. and Zenk, W.: Large lenses of highly saline Mediterranean Water, J. Phys. Oceanogr., 14, 1560-1576, 1984.

Armi, L., Hebert, D., Oakey, N., Price, J., Richardson, P., Rossby, H., and Ruddick, B.: Two years of the life of a Mediterranean salt lens, J. Phys. Oceanogr., 19, 354-370, 1989.

Baey, J., Renouard, D., and D'Hiéres, G.: Preliminary results about the stability of an intermediate water current, Deep-Sea Res., 42, 2063-2073, 1995.

Baringer, M. and Price, J.: Mixing and spreading of the Mediterranean outflow, J. Phys. Oceanogr., 27, 1654-1677, 1997.

Barton, E., Inall, M., Sherwin, T., and Torres, R.: Vertical structure, turbulent mixing and fluxes during lagrangian observations of an upwelling filament system off northwest Iberia, Prog. Oceanogr., 51, 249-267, 2001.

Bower, A., Armi, L., and Ambar, I.: Lagrangian observations of meddy formation during a mediterranean undercurrent seeding experiment, J. Phys. Oceanogr., 27, 2545-2575, 1997.

Boyer, T., Levitus, S., Garcia, H., Locarnini, R., Stephens, C., and Antonov, J.: Objective analyses of annual, seasonal, and monthly temperature and salinity for the World Ocean on a $0.25^{\circ}$ grid, Int. J. Climatol., 25(7), 931-945, 2005.

Carton, X., Chérubin, L., Paillet, J., Morel, Y., Serpette, A., and Cann, B. L.: Meddy coupling with a dep cyclone in the Gulf of Cadiz, J. Mar. Sys., 32, 13-42, 2002.

Chérubin, L., Carton, X., Paillet, J., Morel, Y., and Serpette, A.: Instability of the Mediterranean Water Undercurrents southwest of Portugal: Effects of baroclinicity and of topography, Oceanol. Acta, 23(5), 551-573, 2000.

Drillet, Y., Bourdalle-Badie, R., Siefridt, L., and LeProvost, C.: Meddies in the Mercator North Atlantic and Mediterranean Sea eddy-resolving model, J. Geophys. Res., 110, C03016, doi:10.1029/2003JC002170, 2005.

Eames, I. and Flór, J.: Fluid transport by dipolar vortices, Dynam. Atmos. Oceans, 28, 93-105, 1998.

Fedorov, K.: Mushroom-like currents (vortex dipoles) in the ocean and in a laboratory tank, Ann. Geophys. B-Terr. P., 4, 507-516, 1986.

Fiúza, A.: The Portuguese coastal upwelling system, in: Actual problems of Oceanography in Portugal, Junta Nacional de Investigação Científica e Tecnológica, Lisbon, Portugal, 45-71, 1982.

Fiúza, A.: Upwelling patterns off Portugal, in: Coastal Upwelling: its sediment record, edited by: Suess, E. and Thiede, J., Plenum Press, 85-98 1983.

Flierl, G., Larichev, V., McWilliams, J., and Reznik, G.: The dynamics of baroclinic and barotropic solitary eddies, Dynam. Atmos. Oceans, 5, 1-41, 1980.

Ginzburg, A., Kostianoy, A., Nezlin, N., et al.: Anticyclonic eddies in the northwestern Black Sea, J. Mar. Sys., 32, 91-106, 2002.

Haynes, R., Barton, E., and Pilling, I.: Development, persistence, and variability of upwelling filaments off the Atlantic coast of the Iberian Peninsula, J. Geophys. Res., 98(C12), 22681-22692, 1993.

Kalnay, E., Kanamitsu, M., Kistler, R., and coauthors: The NCEP/NCAR 40-year reanalysis project, B. Am. Meteor. Soc., 77, 437-470, 1996. 
Käse, R. and Zenk, W.: Reconstructed mediterranean salt lens trajectories, J. Phys. Oceanogr., 17, 158-163, 1989.

Käse, R. and Zenk, W.: Structure of the Mediterranean Water and meddy characteristics in the northeastern Atlantic, in: The Warmwatersphere of the North Atlantic Ocean, edited by: Krauss, W., Gebrüder Borntraeger, Berlin Stuttgart, 365-395, 1996.

Käse, R., Beckmann, A., and Hinrichsen, H.: Observational evidence of salt lens formation in the Iberian Basin, J. Geophys. Res., 94, 4905-4912, 1989.

Large, W., McWilliams, J., and Doney, S.: Ocean vertical mixing: a review and a model with a nonlocal boundary layer parameterization, Rev. Geophys., 32, 363-403, 1994.

LeTraon, P. and Ogor, F.: ERS-1/2 orbit improvement using TOPEX/POSEIDON: the $2 \mathrm{~cm}$ challenge, J. Geophys. Res., 103, 8045-8057, 1998.

LeTraon, P., Nadal, F., and Ducet, N.: An improved mapping method of multi-satellite altimeter data, J. Atmos. Ocean. Tech., 25, 522-534, 1998.

Marshall, J., Adcroft, A., Hill, C., Perelman, L., and Heisey, C.: A finite-volume, incompressible Navier Stokes model for studies of the ocean on parallel computers, J. Geophys. Res., 102, 57535766, 1997.

Mied, R., McWilliams, J., and Lindemann, G.: The generation and evolution of mushroom-like vortices, J. Phys. Oceanogr., 21, 489-510, 1991.

Ochoa, J. and Bray, N.: Water mass exchange in the Gulf of Cadiz, Deep-Sea Res., 38, 465-503, 1991.

Oliveira, P., Serra, N., Fiúza, A., and Ambar, I.: A study of meddies using simultaneous in-situ and satellite observations, in: Satellites, Oceanography and Society, edited by: Halpern, D., vol. 63, Elsevier Oceanography Series, 125-148, 2000.

Oliveira, P., Nolasco, R., Dubert, J., Moita, T., and Peliz, A.: Surface temperature, chlorophyll and advection patterns during a summer upwelling event off central Portugal, Cont. Shelf Res., 29, 759-774, 2009.

Paillet, J., Cann, B. L., Serpette, A., Morel, Y., and Carton, X.: Real-time tracking of a Galician meddy, Geophys. Res. Lett., 26, 1877-1880, 1999.

Peliz, A., Santos, A., Oliveira, P., and Dubert, J.: Extreme cross-shelf transport induced by eddy interactions southwest of Iberia in winter 2001, Geophys. Res. Lett., 31, L08301, doi:10.1029/2004GL019618, 2004.

Pingree, R.: The droguing of meddy Pinball and seeding with ALACE floats, J. Mar. Biol. Assoc. UK, 75, 235-252, 1995.

Pingree, R. D. and Cann, B. L.: A shallow meddy (a smeddy) from the secondary Mediterranean salinity maximum, J. Geophys. Res., 98, 20169-20185, 1993.

Prater, M. and Sanford, T.: A meddy off Cape St. Vincent. Part I: Description, J. Phys. Oceanogr., 24, 1572-1586, 1994.

Relvas, P., Barton, E., Dubert, J., Oliveira, P., Peliz, A., Silva, J., and Santos, A.: Physical oceanography of the western Iberia ecosystem: latest views and challenges, Prog. Oceanogr., 74, 149-173, 2007.
Richardson, P., Bower, A., and Zenk, W.: A census of meddies tracked by floats, Prog. Oceanogr., 45, 209-250, 2000.

Røed, L. P. and Shi, X.: A numerical study of the dynamics and energetics of cool filaments, jets, and eddies off the Iberian Peninsula, J. Geophys. Res., 104(C12), 29817-29841, 1999.

Sadoux, S., Baey, J., Fincham, A., and Renouard, D.: Experimental study of the stability of an intermediate current and its interaction with a cape, Dynam. Atmos. Oceans, 31, 165-192, 2000.

Sanchez, R., Relvas, P., Martinho, A., and Miller, P.: Physical description of an upwelling filament west of Cape St. Vincent in late October 2004, J. Geophys. Res., 113, C07044, doi:10.1029/2007JC004430, 2008.

Santos, A., Peliz, A., Dubert, J., Oliveira, P., Angélico, M., and Ré, P.: Impact of a winter upwelling event on the distribution and transport of sardine (Sardina Pilchardus) eggs and larvae off western Iberia: a retention mechanism, Cont. Shelf Res., 24, 149-165, 2004.

Schauer, U.: A deep saline cyclonic eddy in the west European basin, Deep-Sea Res., 36, 1549-1565, 1989.

Schultz-Tokos, K. and Rossby, T.: Kinematics and dynamics of a mediterranean salt lens, J. Phys. Oceanogr., 21, 879-892, 1991.

Schultz-Tokos, K., Hinrichsen, H., and Zenk, W.: Merging and migration of two meddies, J. Phys. Oceanogr., 24, 2129-2141, 1994.

Serra, N.: Observations and numerical modelling of the Mediterranean Outflow, in: Ph.D. Thesis., University of Lisbon., p. 234, 2004.

Serra, N. and Ambar, I.: Eddy generation in the Mediterranean undercurrent, Deep-Sea Res. Pt. II, 49, 4225-4243, 2002.

Serra, N., Sadoux, S., Ambar, I., and Renouard, D.: Observations and laboratory modeling of meddy generation at Cape St. Vincent, J. Phys. Oceanogr., 32, 3-25, 2002.

Serra, N., Ambar, I., and Käse, R.: Numerical modelling of the Mediterranean Water splitting and eddy generation, Deep-Sea Res. Pt. II, 52, 383-408, 2005.

Shi, X. and Røed, L.: Frontal instabilities in a two-layer, primitive equation ocean model, J. Phys. Oceanogr., 29(5), 948-968, 1999.

Sousa, F. and Bricaud, A.: Satellite-derived phytoplankton pigment structures in the Portuguese upwelling area, J. Geophys. Res., 97(C7), 11343-11356, 1992.

Stammer, D., Hinrichsen, H., and Käse, R.: Can meddies be detected by satellite altimetry?, J. Geophys. Res., 96, 7005-7014, 1991.

Swallow, J.: A deep eddy off cape St. Vincent, Deep-Sea Res., 16, 285-295, 1969.

Velasco-Fuentes, O. and van Heijst, G.: Experimental study of dipolar vortices on a topographic $\beta$-plane, J. Fluid Mech., 259, 79106, 1994.

Zenk, W., Schultz-Tokos, K., and Boebel, O.: New observations of meddy movement south of the Tejo Plateau, Geophys. Res. Lett., 19, 2389-2392, 1992. 